\title{
Effect of the morphology of the martensite - austenite phase on fracture of the weld heat affected zone in vanadium and niobium microalloyed steels
}

\section{Y. Li* and T.N.Baker}

Metallurgy and Engineering Materials Group, Department of Mechanical Engineering, University of Strathclyde, Glasgow G1 1XN, U.K.

now Vanitec, Winterton House, High Street, Westerham, Kent, TN16 1AQ, UK;

\begin{abstract}
In multipass welding, the intercritically reheated coarse grained heat affected zone demonstrates the worst toughness in welded joint, since it contains a high-carbon martensite with some retained austenite, known as M-A phase, which is brittle and associated with the high cooling rates following welding.

The purpose of the present work was to explore those aspects of the morphology of the M-A phase which determined the ease or otherwise of crack development in welded vanadium and niobium high strength low alloy steels.

Four steels were subjected to heat treatment to simulate the microstructure of an intercritically reheated coarse grained heat affected zone (IC CG HAZ). The toughness of the simulated IC CG HAZ was assessed using both Charpy and CTOD tests. Microstructural features were characterised by scanning and transmission electron microscopy and optical microscopy. Fractographic examination of the Charpy and CTOD specimens were carried out to understand the micromechanism of fracture under different microstructural and test conditions. Evidence of both cracking and debonding of M-A phase and carbides was found, and many of the
\end{abstract}


cracks appeared to develop by linking-up of voids resulting from debonding. The importance of the dihedral angle, $2 \theta$, in determining the interfacial energy of the two main morphologies of the M-A phase, blocky and elongated stringer particles, was considered. While both carbides and inclusions were observed, these features appear to have a minor role in determining the degree of toughness of the steels.

Key Words

Coarse grained heat affected zone, intercritically reheated coarse grained heat affected zone, martensite-austenite phase, heat- affected- zone toughness, particle debonding.

Corresponding author, e-mail neville.baker@strath.ac.uk 


\section{$\underline{\text { Introduction }}$}

Alloy composition and microstructure are known to have a strong influence on toughness, particularly in body centred cubic alloys such as microalloyed steels. Microstructural features which are important to toughness are grain size and the volume fraction and size of local brittle regions, which include carbides and inclusions in as-rolled ferrite - pearlite steels, and M-A phase, which is a highcarbon martensite with some retained austenite, in the heat affected zone (HAZ) of welded carbon steels. These features are well established as having a controlling effect on the impact transition temperature of steels, which is also influenced by the carbon, manganese and silicon levels. Microcracks are initiated both by the fracture of brittle particles and by the separation of particles and matrix along interfaces ${ }^{1}$, while grains having both low and high misorientations, are known to provide different levels of resistance to the propagation of cracks. In ferrite-pearlite steels, Gorrissen $^{2}$ proposed that grain refinement of ferrite was the main source of improved toughness, and in his work this was related to the level of the manganese addition. The first authors to associate brittle fracture in low carbon steels, $<0.25 \mathrm{wt} \% \mathrm{C}$, at low temperatures with the cracking of cementite films, were Allen et $\mathrm{al}^{3}$. It is now well accepted that in ferrite -pearlite steels, the thickness of cementite is a major factor controlling the impact transition temperature (ITT) ${ }^{4-9}$. In the models of Almond et $\mathrm{al}^{10}$ and Petch ${ }^{11}$, both of which predict the fracture stress in terms of microstructural parameters, terms for average grain size and average carbide thickness are included. While Petch ${ }^{11}$ did not produce experimental data to support his model, in a subsequent paper, Bingley and Siwecki ${ }^{12}$ analysed the data from three carbon steels using a modified Petch approach. They obtained a good agreement between predicted and experimental ITT when they replaced the average grain size by the average of the 
largest $20 \%$ of the grains and also used the maximum carbide thickness. These modifications were confirmed in further work by Bingley ${ }^{13}$. On the other hand, Mintz ${ }^{14}$ found that using his experimental average grain size and the average value of thickness of the 10 largest carbides from a total of 100 carbide measurements, the original Petch model ${ }^{11}$ gave a better prediction for cleavage strength than that of Almond et al ${ }^{10}$. Both the Petch and Almond models showed that grain size and carbide thickness influence both the Charpy V-notch ITT and the cleavage fracture strength. In his model, Petch ${ }^{11}$ considered that fracture starts with a dislocation pileup on a slip plane, followed by a catastrophic collapse of the pile-up as an avalanche of dislocations into a non-equilibrium crack. When a crack does form, its breakout occurs across a carbide and is unstable and static equilibrium is lost. Therefore the cracking of the hard particle is central to the Petch model. Much earlier experimental work by Liu and Gurland ${ }^{1}$, who carried out tensile testing at room temperature on spheroidised steels over a wide range of carbon contents from 0.065 to $1.46 \mathrm{wt} \%$, found that the initiation of fracture occurred either through cracking of carbide particles or by decohesion at the particle -matrix interfaces. They concluded that the hard particles provided the conditions favourable for the nucleation of cracks, namely high stress concentrations, low local ductility or low surface energy. It was also noted that the larger particles broke preferentially. While most of the published research considered carbide cracking to be responsible for fracture initiation, Stevenson ${ }^{15}$, studying an $0.05 \% \mathrm{C}$ steel, observed a change from particle cracking in the asquenched state, to decohesion at the particle -matrix interface following tempering. He attributed this change to a reduction in carbon in solution as a result of tempering. The toughness of high strength low alloy (HSLA) steels generally degenerates due to the influence of a welding thermal cycle. At low temperatures, this degradation has 
been attributed to the formation of local brittle zones in the welded joint. The heat affected zone is in many cases considered to be the most critical part of a weld. For single-pass welding, the region of lowest toughness is normally the coarse grained heat affected zone.This is due to the formation of unfavourable microstructures such as ferrite side-plates (i.e. upper bainite and Widmanstatten ferrite) or grain boundary ferrite $^{16,17}$. During multipass welding, the HAZ formed by the previous welding heat cycle is modified by the subsequent thermal cycles, forming localised and discontinuous zones. The intercritically reheated coarse grained heat affected zone is found to demonstrate the worst toughness in welded joint, since it contains M-A phase ${ }^{18-22}$. The M-A phase plays a significant role in the government of the fracture toughness of the HAZ and causes a sudden decrease in toughness because of the inherent brittle nature and crack susceptibility of martensite ${ }^{22,23}$. It has been reported that the toughness of the IC CG HAZ is predominantly controlled by the size and volume fraction of the high carbon M-A phase ${ }^{22,23}$. However, it also found that the loss in toughness is not solely due to the presence of M-A phase, but is related to the morphology and distribution of the M-A constituent, and the matrix microstructure ${ }^{24,25}$. An alternative explanation for the loss in toughness was proposed by Yokoyama and Nagumo ${ }^{26}$ who do not specify the M-A phase per se , but argued that 'the critical stage determining fracture toughness is the initiation of brittle fracture at intersections of small bainitic ferrite regions in a mixed area of bainitic ferrite and quasi polygonal ferrite, neighbouring coarse bainitic ferrite. The constraint imposed by slip propagation induces deformation microstructures that give rise to an increase in the defect density acting as the crack nuclei, but to date , direct evidence and quantification verification of strain concentration among the microstructural constituents remains un-established '. The influence of the matrix 
microstructure on the toughness in the IG CG HAZ was also emphasised by Qiu et al 27. They found that 'for both static and dynamic loading conditions, cracks in the IG CG HAZ initiated at the intersection of bainitic ferrite packets with different orientations, followed by propagation in cleavage. Furthermore, on some crack propagation regions, adjacent cleavage facets were connected by shear, thus producing dimple zones.' A more recent paper incorporated both the M-A phase and critical stress model approaches to understand the loss in toughness in the HAZ of low carbon steels ${ }^{28,29}$. Lambert-Perlade et al ${ }^{28}$ found that the largest ductile fracture dimples were associated with small $\mathrm{CaS}$ or Ca-rich or Al-rich oxide inclusions, while M-A phase of around $2 \mu \mathrm{m}$ in length, in addition to initiating cleavage fracture was responsible for nucleating the smallest dimples. They argued that the damage micromechanaism acting at M-A constituents depends on the local stress triaxiality ratio. They also found that the nature of the particles, which were mainly elongated austenite particles located between bainite laths or brittle blocky martensite particles, only plays an important role at low strain $(<5 \%)$ or low stress triaxiality ${ }^{29}$. For low mean values of stress, $\tau$, $\left(\tau_{\text {mean }}<1.2\right)$, damage initiated by interfacial decohesion between M-A particles and the surrounding bainitic matrix, most often appeared at the edges of the M-A particles. At a 'high stress triaxiality ratio' all the M-A particles transformed to martensite during the test and became brittle. For higher values of $\tau$, damage initiated by brittle fracture (cracking) of the M-A constituents. Competing effects between M-A/ matrix interfacial decohesion and M-A particle cracking, and bainitic packets in predicting fracture toughness values were accounted for using a micromechanical model, with varying success ${ }^{28}$. 'For temperatures higher than $170^{\circ} \mathrm{C}$, cleavage fracture was controlled by the propagation of microcracks initiated near M-A constituents, while the damage mechanism leading to crack initiation 
(fracture of the M-A particles vs decohesion from the matrix) depends on the local stress and strain state which are influenced by the kind of test and the test temperature $^{28}$.

In previous work by the present authors on the same group of four steels studied here, the effect of steel composition, in terms of the vanadium and niobium additions, on the area fraction and size of M-A phase was reported ${ }^{25}$. The work showed that raising the level of vanadium from 0.05 to $0.11 \mathrm{wt}-\%$ resulted in a greater area fraction of the M-A phase, larger average and maximum sizes of M-A particles, significantly more fields containing the M-A phase and a deterioration in toughness. However, the addition of $0.031 \% \mathrm{Nb}$ produced the largest size of M-A particles and the greatest area fraction for the group of steels considered in the present work, and with one exception, the poorest toughness data in the study.

Unlike ferrite -pearlite structures, where predictive equations of strength and toughness are based on a knowledge of steel chemical composition combined with microstructural parameters, this has not been achieved to- date for ICCGHAZ containing M-A phase. However, the phenomenon of toughness degradation of the IC CG HAZ associated with the M-A phase as described above is well established, although the mechanism by which this occurs in microalloyed steels is still unclear. The present paper considers in more detail the role of the morphology of the microstructural constituents on the fracture toughness in these steels.

\section{Experimental Methods}

The compositions of the steels studied are given in weight percent in Table 1.They were based on $0.1 \% \mathrm{C}, 1.4 \% \mathrm{Mn}, 0.2 \% \mathrm{Si}, 0.03 \% \mathrm{Al}$ and $0.005 \% \mathrm{~N}$ steels with microalloying additions of $\mathrm{V}$ or $\mathrm{Nb}$. The steels were vacuum melted, cast to give 50 $\mathrm{Kg}$ ingots, and subsequently controlled rolled to $30 \mathrm{~mm}$ thick plates. Previous welding 
investigations had shown that the IC CG HAZ in a welded joint was so narrow that it was sometimes impossible to prepare test specimens. To overcome this problem, a welding thermal simulation technique was used to generate the microstructures of the IC CG HAZ. The steels were subjected to a double-pass welding thermal simulation. Thermal simulation test blanks $11 \mathrm{~mm} \times 11 \mathrm{~mm}$ x $90 \mathrm{~mm}$ were cut from the subsurface position of each plate, with the test piece axis transverse to the rolling direction. Following thermal simulation, the blanks were machined to a $10 \mathrm{~mm} \times 10$ mm cross section for Charpy or CTOD test pieces. The weld HAZ thermal simulations were performed on a Gleeble 1500 simulator and the thermal cycles used in the simulated double-pass welding in this study are show in Fig 1. The CG HAZ thermal cycle was designed to simulate a submerged arc weld of approximately 3.6 $\mathrm{KJ} / \mathrm{mm}$ heat input in $25 \mathrm{~mm}$ thick plate. This involves heating to a peak temperature $\left(\mathrm{Tp}_{1}\right)$ of $1350^{\circ} \mathrm{C}$ at a rate of approximately $480^{\circ} \mathrm{C} / \mathrm{s}$ and holding at peak temperature for $0.35 \mathrm{~s}$, followed by cooling between $800^{\circ} \mathrm{C}$ and $500^{\circ} \mathrm{C}\left(\Delta \mathrm{t}_{8 / 5}\right)$ in $24 \mathrm{~s}$. The intercritical cycles were conducted at peak temperatures $\left(\mathrm{Tp}_{2}\right)$ of 750 and $800^{\circ} \mathrm{C}$ respectively, and the heating rates, the times at peak temperature and the cooling rates $\left(\Delta \mathrm{t}_{8 / 5}\right)$ were the same as in the CG HAZ thermal cycle. The peak temperatures were chosen to be similar to those reported in the literature, which showed a reduced toughness due to M-A formation in this temperature interval ${ }^{24} 30,31$. There was some variation in the peak temperature attained in both thermal cycles, and samples were only accepted if the deviations from the aimed peak temperatures were within $\pm 10^{\circ} \mathrm{C}$. The thermally simulated test blanks were etched to reveal the position of the HAZ. Charpy test pieces were notched with a ' $\mathrm{V}$ ' notch of $2 \mathrm{~mm}$ depth and the notch tip placed in the centre of the HAZ. Charpy impact tests were performed in accordance with BS EN 10045 to produce a complete transition curve. The test temperatures were 
in the range $-80^{\circ} \mathrm{C}$ to $60^{\circ} \mathrm{C}$. CTOD test pieces were also produced from the thermal simulated test blanks with a $3 \mathrm{~mm}$ deep through-thickness notch cut into the sample 26. They were tested over the temperature range $\sim-160^{\circ} \mathrm{C}$ to $60^{\circ} \mathrm{C}$, following BS 7448:1991, to produce a complete ductile-brittle transition curve. The Figs $2 \mathrm{a}$ and $2 \mathrm{~b}$ are schematic diagrams which show the positions from which the metallographic and fracture surface samples were taken.

The microstructures of the IC CG HAZ were examined by optical microscopy, scanning electron microscope (SEM) and transmission electron microscope (TEM). The size and the area fraction of the M-A phase in the IC CG HAZ were measured from SEM micrographs of metallographically prepared specimens at a magnification of 5000 times using an image analyzer. At least 300 particles were measured for each of the steels. The fracture surfaces of fracture toughness test specimens were observed with a SEM. To identify the microstructural features of the brittle fracture initiation, the fracture surfaces were etched with $2 \%$ nital. Vertical sections of fractured Charpy or CTOD specimens were also examined to clarify if cleavage fracture was related to M-A constituents particles. Fractured halves were first nickelplated to avoid rounding during polishing and then sectioned longitudinally.

\section{Results}

\section{Toughness in the simulated HAZ}

The effects of vanadium and niobium on the 50J ITT are shown in Fig 3. The CG HAZ Charpy impact transition temperatures were similar for the four steels, except that steel LV had a slightly lower $50 \mathrm{~J}$ ITT of $-70^{\circ} \mathrm{C}$ compared with the others. However, the Charpy impact toughness of all the steels deteriorated in the simulated ICGC HAZ. The $\mathrm{Nb}$ steel exhibited a greater degradation of impact toughness after the $800^{\circ} \mathrm{C}$ intercritical cycle, with a $50 \mathrm{~J} \mathrm{ITT} \mathrm{of}+10^{\circ} \mathrm{C}$. Steel LV had a superior impact 
toughness to the other steels in both the CG HAZ and IC CG HAZ $750^{\circ} \mathrm{C}$ and $800^{\circ} \mathrm{C}$ conditions. In all three cases, the impact toughness decreased as the vanadium content increased to $0.11 \%$. A similar set of results was recorded following $0.1 \mathrm{mmCTOD}$ testing, which was reported previously ${ }^{25}$.

\section{Observations and quantification of microstructure of the simulated HAZ}

The M-A phase was observed by SEM in various forms in the IC CG HAZ in all the four steels examined. Four main types of M-A particles were identified :(a) blockylike M-A particles, also described in the literature as islands ${ }^{24,32}$, (b) elongated stringer particles, (c) connected or nearly connected M-A particles and (d) M-A-C structure consisting of an M-A constituent and a second phase (carbide and ferrite). The blocky-like M-A particles were mostly situated along the prior austenite grain boundaries and polygonal ferrite grain boundaries, while the M-A constituent in a stringer form, was found along bainitic-ferrite lath boundaries. Both (a) and (b) types of M-A are shown in Fig.4a. These blocky M-A particles were typically $0.5 \sim 3 \mu \mathrm{m}$ in size, whereas the elongated stringer particles were $5 \sim 10 \mu \mathrm{m}$ in length and $0.5 \sim 2$ $\mu \mathrm{m}$ wide. The connected or nearly-connected M-A particles were observed on prior austenite grain boundaries (Fig.4b) and also on bainitic lath boundaries.

An M-A-C structure consisting of an M-A constituent and a second phase (carbide and ferrite) is seen in the IC CG HAZ (Fig 4c). The carbide was precipitated on the bainitic lath boundaries and on polygonal ferrite boundaries and it has two morphologies, stringers or broken particles.

TEM examination and SAED of the specimens revealed evidence of cementite and martensite within the IC CG HAZ of the steels. The cementite was found both on the lath boundaries, and within the laths, at C, Fig 5. A twinned morphology, also found 
by Akselsen ${ }^{11}$, characteristic of high carbon martensite, is present in the bright and dark field micrographs, Figs6a and b.

The distribution of M-A particles in prior austenite grains is collated in Fig 7, while Fig 8 shows data for M-A particles on prior austenite grain boundaries. Both sets of data were obtained from specimens prepared as shown in Fig2a. After the $800^{\circ} \mathrm{C}$ cycle, M-A phase was observed in $100 \%$ of the fields of steel $\mathrm{Nb}$ and about $90 \%$ of the fields in the other steels. The number of fields containing stringer M-A particles was significantly higher in steels $\mathrm{Nb}$ and $\mathrm{C}, 40 \%$ and $38 \%$, than in steels $\mathrm{V}$ and VL, $13 \%$ and $15 \%$. Following the $750{ }^{\circ} \mathrm{C}$ cycle, the number of fields containing M-A phase was high in steel V,97\%, but lower in steels VL,79\% and C,80\%. There were fewer stringer M-A particles in steel VL, $16 \%$, than the other steels which contained $\sim 25 \%$. Also there were more fields with M-A phase in the IC CG HAZ of the specimens reheated $800^{\circ} \mathrm{C}$ than in the IC CG HAZ of those reheated $750^{\circ} \mathrm{C}$. In the case of the M-A phase distributed on the prior austenite grain boundaries, for the $800^{\circ} \mathrm{C}$ thermal cycle, the percentages of the boundaries with M-A particles and with nearly- connected M-A particles were the highest in steel $\mathrm{Nb}, 100 \%$ and $42 \%$, while the lowest were present in steel VL, $69 \%$ and $12 \%$ respectively. The corresponding figures for steels V and C were $88 \%, 80 \%$ and $25 \%, 20 \%$.A similar trend was found in the steels after undergoing the $750^{\circ} \mathrm{C}$ cycle, but as seen in Fig 7, fewer M-A particles were associated with the boundaries. In summary, the percentages of prior austenite grain boundaries with M-A particles and with nearly- connected M-A particles were the highest in steel $\mathrm{Nb}$ as were the numbers of stringer M-A particles, and the lowest in steel LV. 


\section{Crack initiation sites.}

To identify crack initiation and the microstructural features near the initiation sites, fracture surfaces before and after etching were examined by SEM. Fig. 9 shows a fracture surface of a Charpy specimen subjected to the IC CG HAZ thermal cycle. At the initiation site, a narrow dimpled region of varying width, labelled IS, was observed. A transition in the fracture mode from ductile to cleavage was evident during crack advancement. The fracture mode in the propagation region was primarily cleavage associated with a small extent, $\sim 10 \%$, of ductile tearing. All the steels exhibited irregular facets in the cleavage regime. The fracture mode of all four steels was identical and it was a function of test temperature, in terms of a transition from dimple-to-cleavage with a decrease in the temperature ${ }^{25}$. Larger M-A particles were found at or close to the initiation point in the etched fracture surface of both the Charpy impact and the CTOD specimens. An example of the initiation site, labelled IN, on the fracture surface of the Charpy impact specimen, from $\mathrm{V} 750^{\circ} \mathrm{C}$, tested at $20^{\circ} \mathrm{C}$, is shown in Fig. 10 . Closer examination of this site revealed that the initiation occurred from the cracked blocky particles, which can be seen to lie on a prior austenite grain boundary, Fig.11. Fig.12 shows the crack initiation site associated with two closely spaced M-A particles at the top 0fva cleavage river marking. The blocky features correspond in size to the blocky M-A particles seen in the IC CG HAZ. EDX analysis showed there was no detectable compositional variation between these blocky features on the fracture surface and the matrix, which indicates that they are not inclusions. In accordance with other published work ${ }^{24}$, these observations suggest that the blocky features are the M-A constituent. However, Kim et al ${ }^{23}$ consider that these local brittle areas were not M-A, but were solely martensitic islands. 
Examples of fracture surfaces with inclusions as the origin of cracking were also observed. The river marks diverging from the non-metallic inclusions can be seen in Fig.13 and the result of an EDX point analysis of the composition of these inclusions suggested that they were aluminium oxides.

Fracture of the M-A constituent itself was also observed in the IC CG HAZ, as seen in Fig14, which also shows evidence of debonding resulting in a void formed between two closely spaced M-A particles. It is of interest to note that the two cracks seen at C in the blocky particle in Fig 1 or that in Fig 15, have not spread into the matrix, while in Fig 15, the incipient crack, labelled IC, does not even spread across the M-A particle. Presumably, the formation of the void reduced the local stress field to below the critical stress for propagation of these cracks.

Debonding of M-A and of M-A-C particles from the surrounding matrix was found in all the Charpy impact and the CTOD specimens examined. A stringer M-A particle debonded from ferrite matrix resulting in a void, can be seen in Fig. 16. Voids nucleated at the interface of ferrite and carbides and grew mainly along the interfaces. Secondary microcracks were observed close to the fracture surfaces in the Charpy impact and the CTOD specimens. Most of these microcracks were initiated at the interface between the M-A constituent and the matrix. However, cases were observed in which an M-A particle had deflected a cleavage crack, Fig.17, or in some cases even arrested the crack propagation as in Fig18, a feature also reported by Chen et al 32

Furthermore, debonding of carbides was observed in the deformed areas close to the fracture surface. Fig 19 illustrates how growing cavities interact to form large voids and the carbides observed in Fig 20 break in the later stage of void growth because of a considerable amount of plastic deformation in the ferrite matrix. 


\section{Discussion}

\section{Factors influencing the formation of M-A phase}

During the heating stage of the second cycle of the simulated welding of steels shown in Fig 1, dissolution of cementite and nucleation and growth of reverse austenite take place. Austenite nucleates at prior austenite grain boundaries as well as along the interfaces between laths of ferrite. The reversely transformed austenite grows into the ferrite matrix with the carbon flux being supplied from the dissolving cementite. Since the prior austenite grain boundary is initially carbon enriched and is a rapid diffusion path for carbon, more austenite grows faster at the grain boundary than in other areas. Because the heating rate of the weld thermal cycle is high, of the order of $10^{2} \mathrm{deg} \mathrm{s}^{-1}$, and the time in the intercritical temperature region is short, of the order of a few seconds, it is considered that only carbon is partitioned between ferrite and austenite, while the substitutional elements are not partitioned. Therefore, the austenite pool grows under the local para-equilibrium conditions. For steels containing overall carbon contents greater than about $0.06 \mathrm{wt} \%$, the carbon in the MA particles or islands has been found experimentally to be about $1.07-1.32 \mathrm{wt} \%{ }^{33}$. Carbon enrichment increases the hardenability of the austenite, and on cooling, some fraction of the austenite is transformed into twinned martensite, as seen in Fig 6. The fraction of the martensitic transformation depends predominantly on the chemical composition, particularly the niobium and vanadium contents, the concentration of the enriched carbon and the cooling rate during the second thermal cycle ${ }^{16}$. Lee et al ${ }^{16}$ considered that the hardness conferred by the martensite islands was responsible for the deterioration in toughness in the IC GC HAZ. They showed that increasing the $\mathrm{Nb}$ content from $0.014 \mathrm{wt}-\%$ to $0.021 \mathrm{wt}-\%$ for all secondary peak temperatures between 600 and $1200^{\circ} \mathrm{C}$,increased the volume percentage of martensite islands. A 
small addition of $\mathrm{Nb}, \sim 0.02 \mathrm{wt}-\%$, is known to suppress the nucleation of ferrite at prior austenite grain boundaries and therefore increase the volume fraction of martensite or bainite ${ }^{16}$. $\mathrm{Nb}$ has a significantly more powerful effect on hardenability than does $\mathrm{V}$.Amin and Pickering ${ }^{34}$ considered that 'because $\mathrm{Nb}$ is a larger atom than $\mathrm{V}$, it segregates more positively to prior austenite grain boundaries than does $\mathrm{V}$, and decreases the diffusion rate and activation energy of carbon diffusion in austenite more than does $\mathrm{V}$ because of its stronger affinity for carbon. These effects all decrease the nucleation rate of ferrite', which they observed.

\section{Cracking and debonding of M-A phase}

Several investigations, for example ${ }^{17,20,24,30}$, have shown that M-A particles are the main cause of a deterioration in the HAZ toughness of welded microalloyed steels, because of their high hardness and crack susceptibility. However, the mechanism by which this occurs is still unclear.

Four mechanisms have been proposed in the literature ${ }^{18,24,32,35,36}$ to explain the cleavage fracture initiated by the M-A constituent. They have been collated by Davis and King ${ }^{20}$ and are given below.

(1) The M-A particle is a brittle phase and cracks readily.

The MA phase is observed as blocky particles, $3-5 \mu \mathrm{m}$ in diameter nucleating at prior austenite boundaries and stringer particles, 0.2 to $1 \mu \mathrm{m}$ width and several microns in length, that develop between bainite/martensite laths. In the present work particles with similar morphology and sizes were found. Davis and $\mathrm{King}^{20,24}$, did not observe cracking of blocky M-A particles and this was also the case in the work of Aihara and Okamotos ${ }^{36}$. These latter authors considered that the lack of crack formation of the M-A phase might be because the M-A phase was somewhat auto-tempered during the cooling stage and therefore recovered its toughness. In the present study, eight 
cases of cracking of both the blocky and the stringer-type of M-A particles were observed on the vertical sections close to the fracture surfaces and also on the fracture surfaces. Examples of cracking of the blocky M-A particle are seen in Figs. 14 and 15 and stringer M-A particles in Fig16, which were observed in the vertical sections of the CTOD specimens, Fig. 2b. Examples of cracking of M-A particles observed on the fracture surface are given in Figs. 10 to 12. As in other work, stringer M-A particles did not appear to provide any effective obstacle to crack propagation ${ }^{20,24}$. In his work, Mintz' regarded cracking of the carbide ${ }^{6-9}$ and martensite films ${ }^{37}$ to be a significant factor in relating microstructure to toughness data. The changes in Charpy impact behaviour were explained by considering the martensite films as being similar to the brittle grain boundary carbides present in the ferrite-pearlite steels. These films readily crack, yet are always thick enough to produce a sufficiently wide crack to render crack propagation easy. The critical event in fracture then becomes the ability to propagate the cracks through the grain boundaries. On the other hand, it is evident that sometimes M-A particles do delay the growth of cracks, as shown in Fig18. This observation would indicate a very complex mixture of the influences of M-A phase on toughness, which have not yet been fully unravelled. Hrivnak et al ${ }^{38,39}$ has also suggested that in some circumstances, M-A constituent could change the direction or even arrest the propagation of a cleavage crack and increase the fracture energy.

\section{(2)Transformation induced tensile residual stresses are produced in the}

surrounding ferrite matrix which assist cleavage fracture.

During the second thermal cycle, austenite islands form at the prior austenite grain boundaries and on cooling, transform to M-A constituent, which is predominantly high carbon martensite. The volume expansion associated with the austenite to martensite transformation will result in significant elastic and plastic strains in the 
surrounding ferrite matrix, which will assist cleavage fracture ${ }^{35}$. This effect will be magnified for the situation of closely spaced M-A particles, where the transformation induced stress fields overlap. Figs 14 and 15 both show a void formed between closely spaced particles.

(3) The M-A phase has a higher hardness than the surrounding ferrite matrix and induces stress concentrations in the neighbouring ferrite matrix. This stress concentration assists cleavage fracture.

On initial loading, both the matrix and M-A particles will deform elastically and no stress concentration will result, as both have the same elastic modulus. On increasing the load, in some areas, as the M-A particles are harder than the matrix, the matrix will begin to deform plastically and shed load into the M-A particles. This may cause the M-A particles to debond from the matrix, as large stresses develop across the interface. In addition, it has been suggested that the M-A/matrix interface may be weakened by carbon segregation ${ }^{15}$. Debonding of both blocky particles is seen in Figs 14 and 15 and elongated stringer MA particles Fig 16.

(4) A microcrack which is formed at the $M-A /$ matrix interface through interface decohesion, then propagates either in a brittle manner or via the linking of other debonded regions.

In the present study, 23 cases of debonding of M-A and M-A-C particles (especially when they were larger in size) from the surrounding matrix were found, similar to that seen in Fig 16, which covered all of the Charpy and the CTOD specimens examined. Debonding was seen also in the intercritically reheated specimens. The linking- up of cavities or voids, which result from debonding, appears to be a most important way in which fracture proceeds in this work. 
Crack initiation occurred mainly by debonding of the M-A phase from ferrite and to a lesser extent, from two closely spaced M-A particles during CTOD and Charpy testing. This latter mechanism was also observed by Davis and King ${ }^{20,24}$. Unlike their work, the present work found large single M- A islands to be the most frequently observed particles associated with a crack. Other researchers, ${ }^{32,33}$ have also found evidence of larger M-A particles debonding and causing failure.

Several pieces of work have suggested that the stress concentrations in the IG CG HAZ are inhomogeneous and this leads to a varying role for the MA phase. Chen et al $^{32}$ considered that high stress concentrations occur close to the boundary between ferrite and the M-A constituent, and they also reported that the larger the size of the M-A island, the smaller the load required to initiate the new crack nucleus.

. At moderate temperatures, this stress results in the interfacial cracking and /or debonding. Lambert-Perlade et $\mathrm{al}^{28}$, suggested that for low mean values of stress, $\tau$ $\left(\tau_{\text {mean }}<1.2\right)$, damage initiated by interfacial decohesion between M-A particles and the surrounding bainitic matrix, most often appeared at the edges of the M-A particles. This is in agreement with the situation found in Figs 14 and 15.With increasing strain, small cracks grow to voids and further develop to deep holes. It was considered that by promoting the initiation of dimples, M-A phase has an adverse effect on ductility and the upper shelf energy in the impact test. At lower temperatures, however, stiffer, blocky M-A, gives rise to concentration and triaxiality of stress at the point near the interface on the ferrite side, and makes the latter crack, which then propagates in a cleavage mode ${ }^{32}$.

C.S Smith ${ }^{40}$ was the first to equate interfacial energies of a precipitate at a grain boundary to the dihedral angle $2 \theta$, and then to related this to the effectiveness of wetting. Davey and Glover ${ }^{41}$ used Smith's relationship to assess the effect of 
manganese content on the dihedral angles and hence interfacial energies of cementite precipitates in a carbon steel. As far as is known, the relation between $2 \theta$ and the corresponding interfacial energies of ferrite and M-A phase morphology has not been studied. It is of interest to note that the dihedral angle between the stringer M-A particles and the ferrite matrix is invariably smaller than in the case of the blocky particle. In the present work, the blocky particles have $2 \theta$ values of $\sim 130-150^{\circ}$, whereas those for the stringer particles are $<90^{\circ}$.

As illustrated in Fig 21a, 20, is related to the interfacial energies $\sigma_{\alpha \alpha}$ and $\sigma_{\alpha \mathrm{MA}}$ by

$$
\cos \theta=\sigma_{\alpha \alpha /} 2 \sigma_{\alpha \mathrm{MA}}
$$

Figs $21 \mathrm{~b}$ and $21 \mathrm{c}$ show examples of the change in the dihedral angle for a blocky MA particle compared with a stringer MA particle.

For the blocky M-A particle in Fig $21 \mathrm{~b}, 2 \theta_{1}=130^{\circ}$, and $\sigma^{\mathrm{b}}$ is the interfacial energy, therefore $\sigma_{\alpha \alpha /} 2 \sigma^{\mathrm{b}}{ }_{\alpha \mathrm{MA}}=\cos \theta_{1}=0.26$, If $F_{b}=\sigma_{\alpha \alpha} / \sigma^{b}{ }_{\alpha M A}$, then $F_{b}=0.52$ and $\sigma_{\alpha \alpha}=0.52 \sigma^{b}{ }_{\alpha M A}$

For the elongated stringer M-A particle in Fig $21 \mathrm{c}, 2 \theta_{2}=30^{\circ}$, and if $\sigma^{\mathrm{s}}$ is the interfacial energy, $\sigma_{\alpha \alpha} / 2 \sigma_{\alpha \mathrm{MA}}^{\mathrm{s}}=\cos \theta_{2}=0.97$

If $F_{\mathrm{s}}=\sigma_{\alpha \alpha} / \sigma^{\mathrm{s}}{ }_{\alpha \mathrm{MA}}$, then $\mathrm{F}_{\mathrm{s}}=1.94$, and $\sigma_{\alpha \alpha}=1.94 \sigma^{\mathrm{s}}{ }_{\alpha \mathrm{MA}}$

Therefore $\sigma_{\alpha \mathrm{MA}}^{\mathrm{b}}=3.7 \sigma_{\alpha \mathrm{MA}}^{\mathrm{s}}$

Therefore for the present data, the interfacial energy of the stringer M-A particle is only $\sim 30 \%$ of that of the blocky M-A particle. 
This indicates that the interfacial energies of the stringer particles are substantially lower than those of the blocky particles and therefore likely to debond more readily from the matrix than blocky M-A particles, which are more likely to crack.

\section{The effect of carbides and inclusions on the HAZ toughness}

In steels containing large discrete carbide particles, such as mild steels or spheroidized plain carbon steels, cleavage fracture is generally nucleated by cracked carbide particles ${ }^{5}$.Dislocation pile-ups will occur at these coarse carbide particles, and the stress intensification at the head of the pile-up, coupled with the tensile stresses applied to induce the pile-ups, eventually cause carbide cracking. The carbide crack itself, however, may be sub-critical with regard to propagation of cleavage fracture into the ferrite matrix. The cracked carbide may then remain in the structure, with the crack being blunted by subsequent plastic deformation of the ferrite. However, if the crack in the carbide is sufficiently large, the crack may propagate through the ferrite matrix. Curry and Knott ${ }^{42}$ concluded that the cleavage fracture stress is broadly proportional to the reciprocal square root of the carbide thickness. Gladman et al ${ }^{43}$ indicated that in low carbon steels cooled at modest rates and having a relatively high transformation temperature, isolated carbides are formed at ferrite grain boundaries. The impact transition temperature is little affected until the carbide attains a thickness of about $2 \mu \mathrm{m}$, and significantly, at carbide thickness of 5-10 $\mu \mathrm{m}$, the impact transition temperature increases by $70-90^{\circ} \mathrm{C}$.

Carbides observed in the simulated IC CG HAZ are seen in Fig. 20 as thin particles and rarely as a film, and they are usually of an order of magnitude thinner than the MA phase. Many instances of cracking are present in Fig 20. However, as the carbides are $\sim 100-200 \mathrm{~nm}$ in thickness, the cracks have not spread into the ferrite matrix. It is therefore believed that they do not have a major initiation role in cleavage fracture in 
the IC CG HAZ. They may be important at a later stage of the fracture, but again through a debonding mechanism. Debonded inclusions, such as those shown in Fig 13 are also considered to play a role in cleavage fracture. Davis and King ${ }^{24}$ suggested a parallel between the behaviour of M-A particles and $\mathrm{MnS}$ and oxide inclusions, in that as inclusions contract more than the matrix during cooling from hot working temperatures, they set up a stress field around them, which also increases the probability of decohesion. Because these inclusions have a low interfacial energy, they debond when the material undergoes plastic deformation. It was shown by Baker and Kavishe ${ }^{44}$ that crack initiation occurs near these MnS debonded inclusions, since they act as local stress concentrators, which results in cracking of carbides, possibly in a similar manner to M-A particles. However, since EDX analysis indicated that the fracture surface area related to inclusions is less than $5 \%$ of the total fracture surface area, they believed that the inclusions play a relatively minor role in controlling the fracture mechanism of the HAZ. A similar conclusion was reached by Lee ${ }^{45}$. In the present work, it was also observed that the density of the inclusions in the IC CG HAZ was much lower than that of M-A phase, therefore, the inclusions are considered to be less important in controlling the toughness.

\section{Conclusions}

The purpose of the present work was to explore those aspects of the morphology of the M-A phase which determined the ease or otherwise of crack development in welded vanadium and niobium high strength low alloy steels. Four mechanisms based around particle cracking and /or debonding have been proposed to explain the cleavage fracture initiated by the M-A constituent and have been collated by Davis 
and King. However, the correlation between these mechanisms and experimental observations are not invariably substantiated and warrant further exploration. In this study, weld HAZ thermal simulations of microalloyed steels with $\mathrm{V}$ and $\mathrm{Nb}$ additions were performed on a Gleeble 1500 simulator and the thermal cycles used in the simulated double-pass welding..

(1) Fracture initiation by both cracking of M-A particles and debonding of M-A and M-A-C particles was observed.

(2) In all four steels studied, four main types of M-A particles were identified by SEM in the simulated IC CG HAZ samples:(a) blocky-like M-A particles, also described in the literature as islands (b) elongated stringer particles, (c) connected or nearly connected M-A particles and (d) M-A-C structure consisting of an M-A constituent and a second phase (carbide and ferrite). The percentages of prior austenite grain boundaries with M-A particles and with nearly- connected M-A particles were the highest in steel $\mathrm{Nb}$ and the lowest in the $0.05 \mathrm{wt}-\% \mathrm{~V}$ steel.

(3) Eight cases of cracking of both the blocky and the stringer-type of M-A particles were observed on the vertical sections close to the fracture surfaces and also on the fracture surfaces. In addition, 23 cases of debonding of M-A and M-A-C particles (in particular when they were larger in size) from the surrounding matrix were found in the intercritically reheated specimens, which covered all of the Charpy and the CTOD specimens examined.

(4) The dihedral angles of blocky and elongated stringer particles were measured and using the relation developed by C.S.Smith equating dihedral angle to the interfacial energy of a particle precipitated at a grain boundary, it was estimated that the interfacial energy of an elongated stringer particle was $\sim 30 \%$ of that of a blocky 
particle. This result supported the view that elongated stringer particles were more likely to debond from the matrix while blocky particles were more likely to crack. (5) Carbides observed in the simulated IC CG HAZ were seen as thin particles and rarely as a film, and were usually of an order of magnitude thinner than the M-A phase. It is believed that, as isolated particles, they do not have a major initiation role in cleavage fracture in the IC CG HAZ. They may be important at a later stage of the fracture, but again through a debonding mechanism,

(6) It was observed that the density of the inclusions in the IC CG HAZ was much lower than that of M-A phase. Therefore debonded inclusions are believed to play a relatively minor role in controlling the fracture mechanism of the HAZ.

(6) The present work suggests that the fracture toughness of the microalloyed steels studied is related primarily to the presence of M-A phase, but that where the triaxial stresses are high, cracking of blocky M-A particles is the most important factor in the initiation of brittle fracture, but in other parts of the microstructure where the triaxial stresses are lower, decohesion associated with stringer M-A particles with a lower interfacial energy develop into voids leading to the formation of cracks.

\section{Acknowledgements}

Financial support from the University of Strathclyde, Swinden Technology Centre, Corus and Vanitec are gratefully acknowledged by YL. Dr D N Crowther and Mr P S Mitchell are thanked for their helpful advice during the course of the work. Aileen Petrie is thanked for formatting some of the figures. 


\section{References}

1 C.T.Liu and J Gurland; Trans ASM 1968, 61, 156-167.

2 J.Görrissen: J. Iron Steel Inst., 1949, 162, 16-28.

3 N.P.Allen, W.P.Rees, B.E.Hopkins and H.R.Tipler: J. Iron Steel Inst., 1953, 174, $108-120$.

4 G.T.Hahn, M.Cohen, B.L.Averbach: J. Iron Steel Inst., 1962, 200, 634-644.

5 C. J. McMahon and M.Cohen: Acta Metall., 1965, 13, 591- 604.

6 B. Mintz, W.B.Morrison and A.Jones: Met.Technol., 1979, 6,252- 260.

7 B. Mintz, W.B.Morrison and R.C.Cochrane: in 'Advances in the physical metallurgy and applications of steels' 222-228, 1982, London, The Metals Society.

8 B. Mintz and P.Campbell: Mater. Sci Technol.:1987, 3, 845-848.

9 B.Mintz, S.Tajik and R.Vipond: Mater. Sci Technol.:1994, 10, 9-96.

10 E.A.Almond, D.H.Timbres and J.D.Embury: $2^{\text {nd }}$ Int. Conf.on 'Fracture', ed P.L.Pratt, vol. 6, 253-, 1969, London, Chapman and Hall.

11 N.J.Petch: Acta Metall., 1986, 34, 1387-1393.

12 M.S.Bingley and T.Siwecki: Proc $8^{\text {th }}$ Int. Conf. relationship on 'Strength of metals and alloys', Tampere, Finland, August 1988,vol.3,1191 - 1196,1988, Oxford, Pergamon.

13 M.S.Bingley: Mater. Sci. Technol., 2001, 17, 700-714.

14 B.Mintz, S.Tajik, F.Kavishe and T.J.Baker: Mater. Sci. Technol., 1991, 7, 1005- 1009. 
15 R.Stevenson: in 'Formable HSLA and Dual Phase Steel', edit. A. T. Davenport 1979, 101-109.

16 Ø. Grong and Ø M. Akselsen, Met.Constr.,1986,18,557-562.

17 Ø.M. Akselsen, Ø. Grong and J. K. Solberg,: Mater. Sci Technol., 1987, 3, 649- 655 .

18 Ø.M. Akselsen, Ø. Grong and G.Rorvik: Scand. J. Metall., 1990, 19, 258-264.

19 S. Lee, B Chun, and D. Kwon: Metall. Trans, 1992, 23A, 2803-2816.

20 C.L.Davis and J.E.King, Metall Trans., 1994, 25A, 563-573.

21 K.Ohya, J.Kim, K. Yokoyama, and M. Nagumo: Metall.Trans.1996, .27A, $2574-2582$.

22 T.Haze, S.Aihara and H.Mabuchi: Accelerated cooling of rolled steel, ed. P.D.Southwick, TMS, Warrendale, PA, 1986,235-247.

23 B.C.Kim, S.Lee, N.J.Kim and D.Y.Lee: Metall.Trans.1991, .22A, 139-149.

24 C.L.Davis and J.E.King: Mater. Sci Technol., 1993, 9, 8-15.

25 Y. Li, D. N.Crowther,M.J.W.Green, P.S.Mitchell and T.N.Baker: ISIJ Inter. $2001,41,46-55$

26 K Yokoyama and M. Nagumo: Metal. Mater. Trans., 1998, 29A, 551-558.

27 H. Qiu, H. Mori, M. Enoki, and T .Kishi:. Metal. Mater. Trans., 2000, 31A, 2785- 2791.

28 A. Lambert-Perlade, A.F.Gourgues, J.Besson,T.Sturel and A.Pineau, Metall. Mater.Trans A2004, 35A, 1039-1053.

29 A. Lambert-Perlade, J.Drillet, A.F.Gourgues, T.Sturel and A.Pineau, Sci.Technol.Welding Joining, 2000, 5, 168-173.

$30 \mathrm{~K}$. Uchino and Y. Ohno, 6th International Conference of Offshore Mechanics and 
Arctic Engineering, Houston, TX, Mar. 1-7, 1987, 159-165.

31 Ø. M. Akselsen, J. K. Solberg and Ø. Grong: Scand. J. Metall, 1988, 17, 194- 200.

32 J.H.Chen, Y.Kituta,T.Araki, M.Yoneda and Y.Matsuda: Acta metall., $1984,32,1779-1788$.

33 R.S.Ranade, F.J.Barbaro, J.G.Williams, P.R.Monroe and P. Krauklis: J.Phys. 1995, 5, C8-311.

34 R.K.Amin and F.B.Pickering: Themomechanical Processing of Microalloyed Austenite, Ed A.J.DeArdo,G.A.Ratz and P.J.Wray, 1982, 377-403, Metall. Soc. AIME, Warrendale, Penn.

35 C.A.N.Lanzillotto and F.B.Pickering: Metal Sci., 1982, 16,371-382.

$36 \mathrm{~S}$. Aihara and K. Okamoto, Influence of Local Brittle Zone on HAZ Toughness of TMCP Steels. In: Bulletin 373, Welding Research Council, New York, NY 1992, 33-43.

37 B.Mintz: Metall. Trans A, 1997, 28A, 2073- 2084.

38 I Hrivnak: F.Matauda and K.Ikeuchi:Trans.of JERI, 1992, 21, 9-31

39 I Hrivnak: ISIJ Inter, 1995, 35, 1148-1156.

40 C.S.Smith, Trans Amer.Inst.Min.Met.Eng., 1948, 175, 15-51.

41 L.T.G.Davy and S.G.Glover:J.Aust.Inst.Met.,1968,13, 71-78.

42 D.A.Curry and J.F.Knott: Metal Sci., 1979, 13,341-345.

43 T.Gladman,D.Dulieu and I.D.McIvor: Proc. 'Microalloying '75', 32-58, 1977, Union Carbide Corp., New York, NY.

44 T.J.Baker and F.P.L.Kavishe: Mater.Sci.Technol.,1986, 2,576-582.

45 S. Lee, B C.Kim, and D. Kwon: Metall. Trans, 1993, 24A, 1133-1141. 


\section{Figure Captions}

1 Simulated weld thermal cycles

2a Schematic diagram showing the position from which metallographic samples were taken.

$2 \mathrm{~b}$ Schematic diagram showing the fracture surface and longitudinal Charpy or CTOD sections which were examined metallographically.

3 Effects of vanadium and niobium on the 50 ITT of GC HAZ and IC GC HAZ of the four steels.

4a SEM micrograph of the simulated IC CG HAZ microstructure shows blockylike M-A particles on prior austenite grain boundary and polygonal ferrite grain boundaries, and stringer M-A particles along bainitic ferrite lath boundaries.

4b SEM micrograph of the simulated IC CG HAZ microstructure shows the connected M-A particles on prior austenite grain boundary.

4c SEM micrograph showing the M-A + upper baintic structure

5 Bright field TEM micrograph showing the M-A-C phase, austenite indicated by A; martensite indicated by $\mathrm{M}$ and carbides indicated by $\mathrm{C}$.

6a Bright field TEM micrograph showing the twinned nature of the M-A phase.

6b Dark field TEM micrograph showing the twinned nature of the M-A phase

7 Distribution of M-A particles in prior austenite grains

8 Distribution of M-A particles on prior austenite grain boundaries

9 SEM fractograph showing the narrow dimple region, labelled IS, at the initiation site and a cleavage fracture region. 
10 SEM fractograph showing the initiation site, labelled IN, on the fracture surface of a Charpy impact specimen.

11 SEM fractograph showing the fracture initiation from particles at a prior austenite boundary and a crack following the prior austenite grain boundary.

12 SEM fractograph showing two closely spaced M-A particles (M-A) at the top of a cleavage river marking indicating the crack initiation site.

13 SEM fractograph showing small inclusions at a cleavage fracture initiation site. 14 SEM micrograph showing a void between two closely spaced M- A particles. Two cracks at $\mathrm{C}$ have not propagated.

15 SEM micrograph showing a void between two closely spaced M-A-C particles. An incipient crack is seen at IC.

16 SEM micrograph showing debonding at ferrite/stringer M-A interface and cracking of the stringer M-A particle

17 SEM micrograph showing a crack which changed direction when meeting an M-A particle

18 SEM micrograph showing a crack stopped by an M-A particle

19 SEM micrograph showing a highly deformed matrix together with debonded carbides on lath boundaries and pores

20 SEM micrograph showing cracked carbides indicated at $\mathrm{C}$.

21 a) Schematic diagram of particle with dihedral angle and surface energies indicated b) blocky MA particle with high dihedral angle c) stringer MA particle with low dihedral angle. 


\begin{tabular}{|l|l|l|l|l|l|}
\hline Code & $\mathrm{C}$ & $\mathrm{Si}$ & $\mathrm{Mn}$ & $\mathrm{P}$ & $\mathrm{S}$ \\
\hline Steel C & 0.092 & 0.20 & 1.41 & 0.005 & 0.004 \\
\hline Steel LV & 0.084 & 0.21 & 1.42 & 0.005 & 0.002 \\
\hline Steel V & 0.094 & 0.21 & 1.44 & 0.005 & 0.003 \\
\hline Steel Nb & 0.100 & 0.19 & 1.40 & 0.005 & 0.002 \\
\hline Code & $\mathrm{Al}$ & $\mathrm{N}$ & $\mathrm{Nb}$ & $\mathrm{V}$ & $\mathrm{B}$ \\
\hline Steel C & 0.039 & 0.0067 & 0.005 & 0.005 & 0.0005 \\
\hline Steel LV & 0.031 & 0.0047 & 0.005 & 0.05 & 0.0005 \\
\hline Steel V & 0.029 & 0.0052 & 0.005 & 0.10 & 0.0005 \\
\hline Steel Nb & 0.031 & 0.0040 & 0.031 & 0.005 & 0.0005 \\
\hline
\end{tabular}

Table 1 Chemical composition of the steels (wt- \%) 


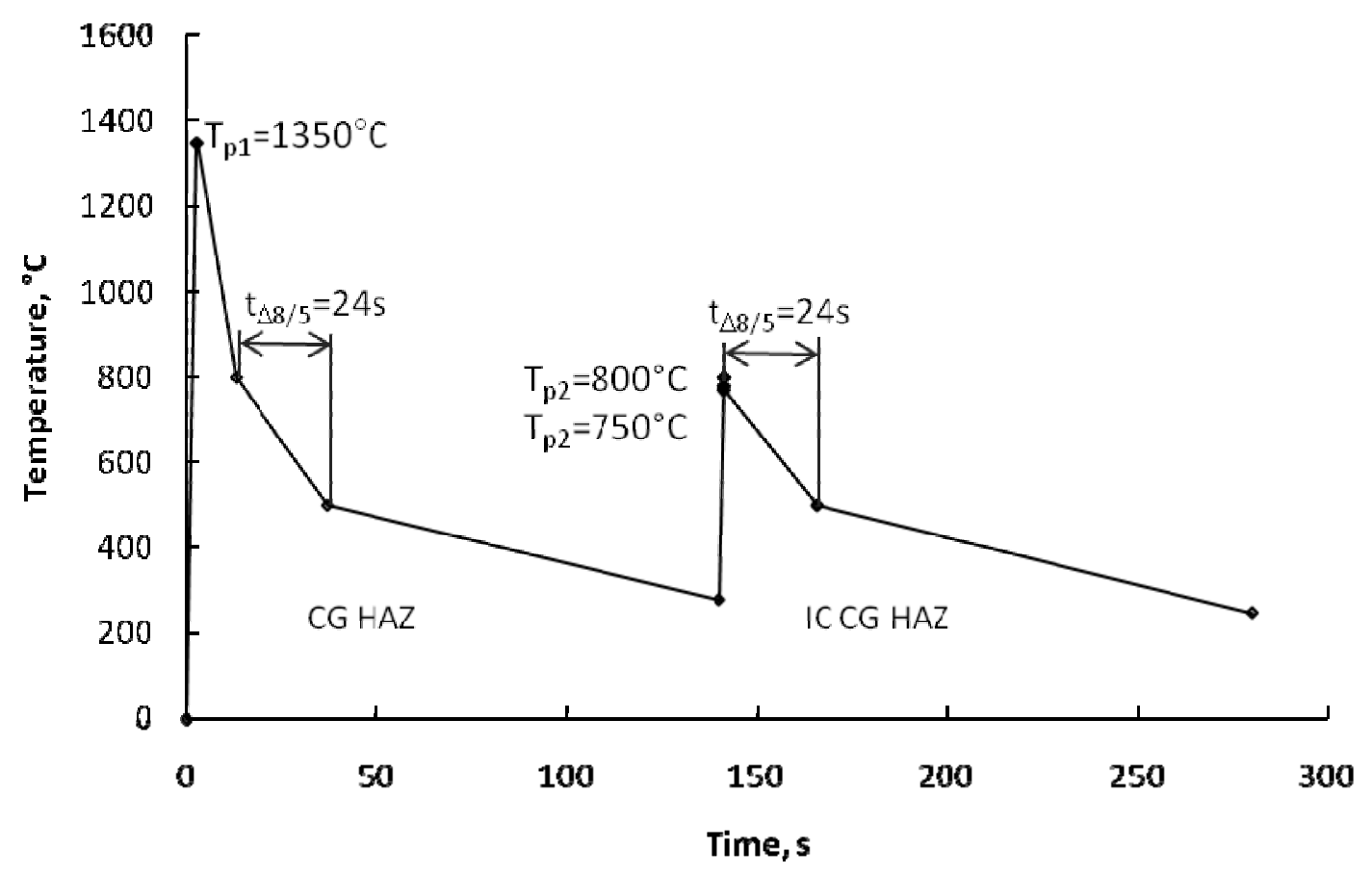

Fig. 1 


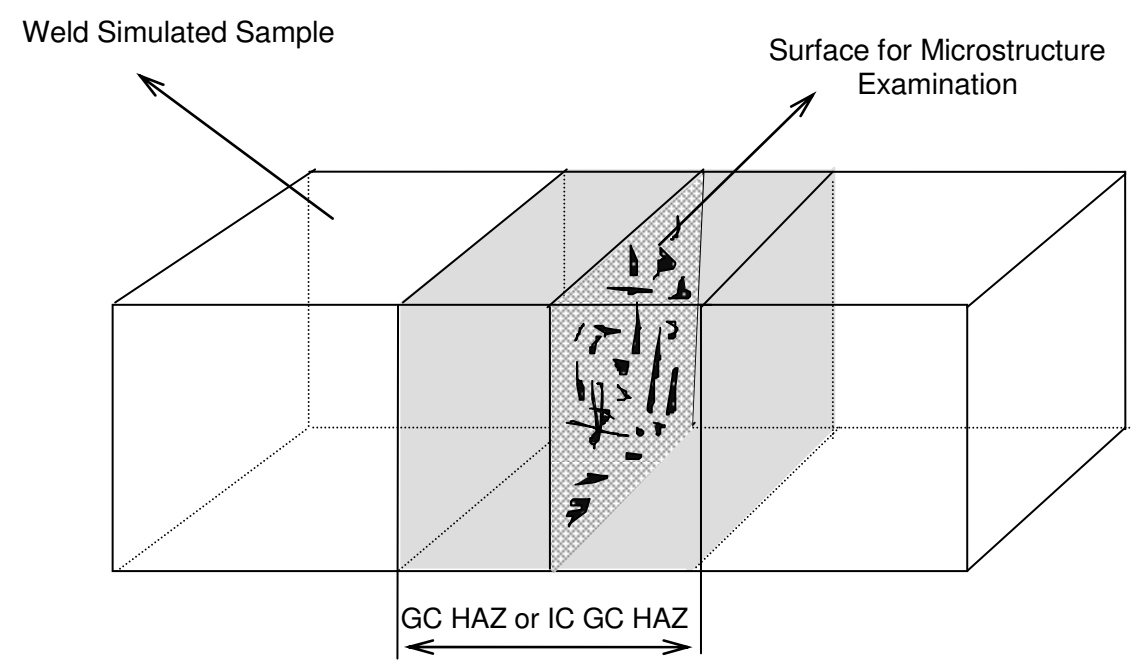

Fig 2a

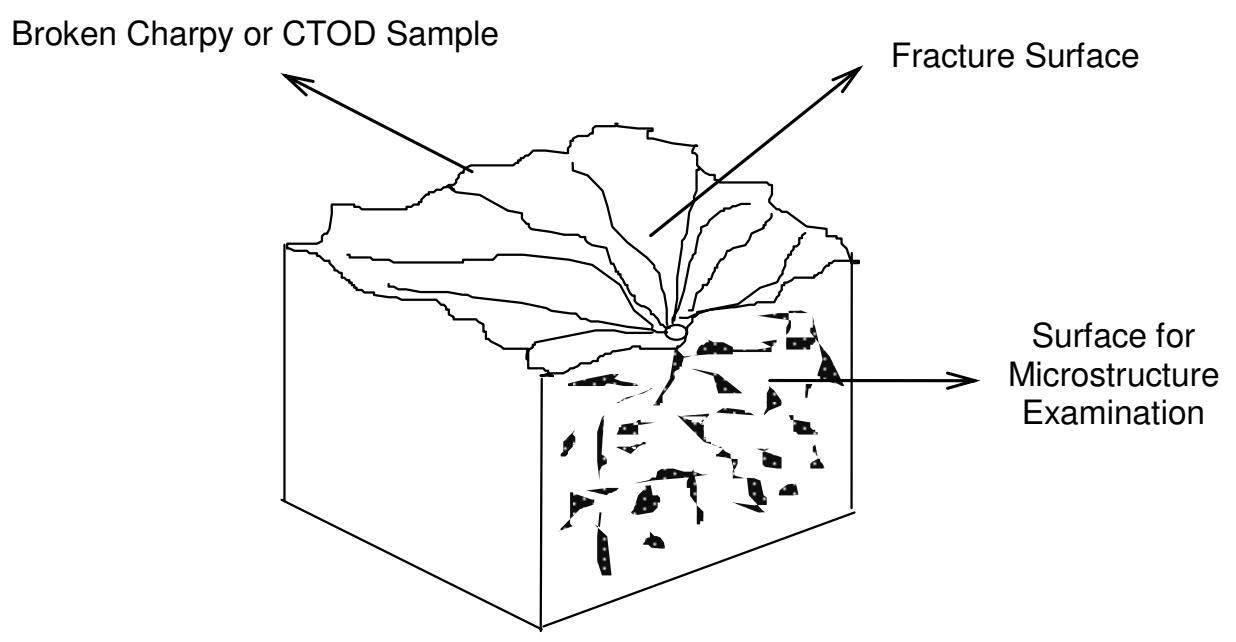

Fig $2 b$ 


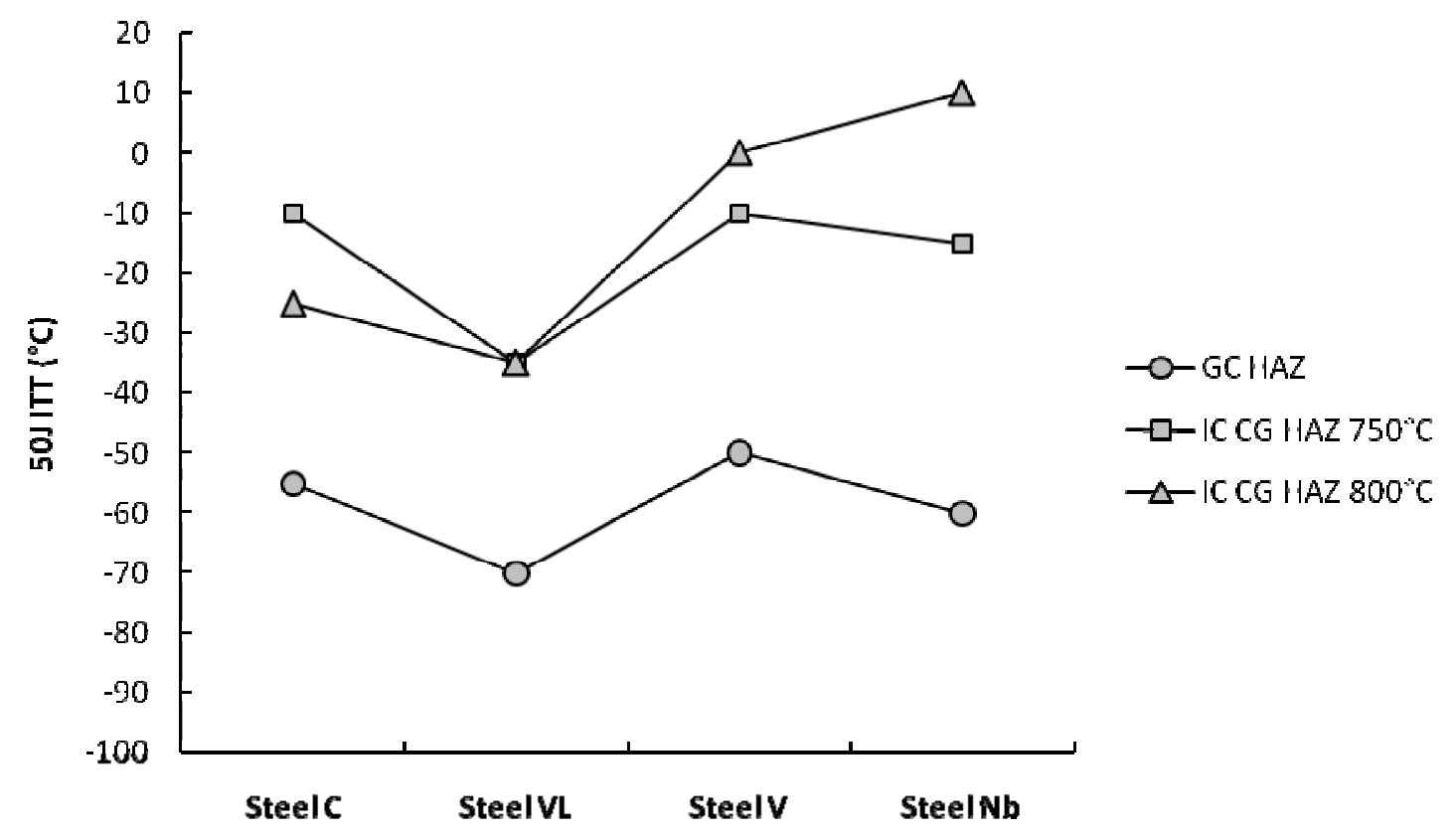

Fig 3 


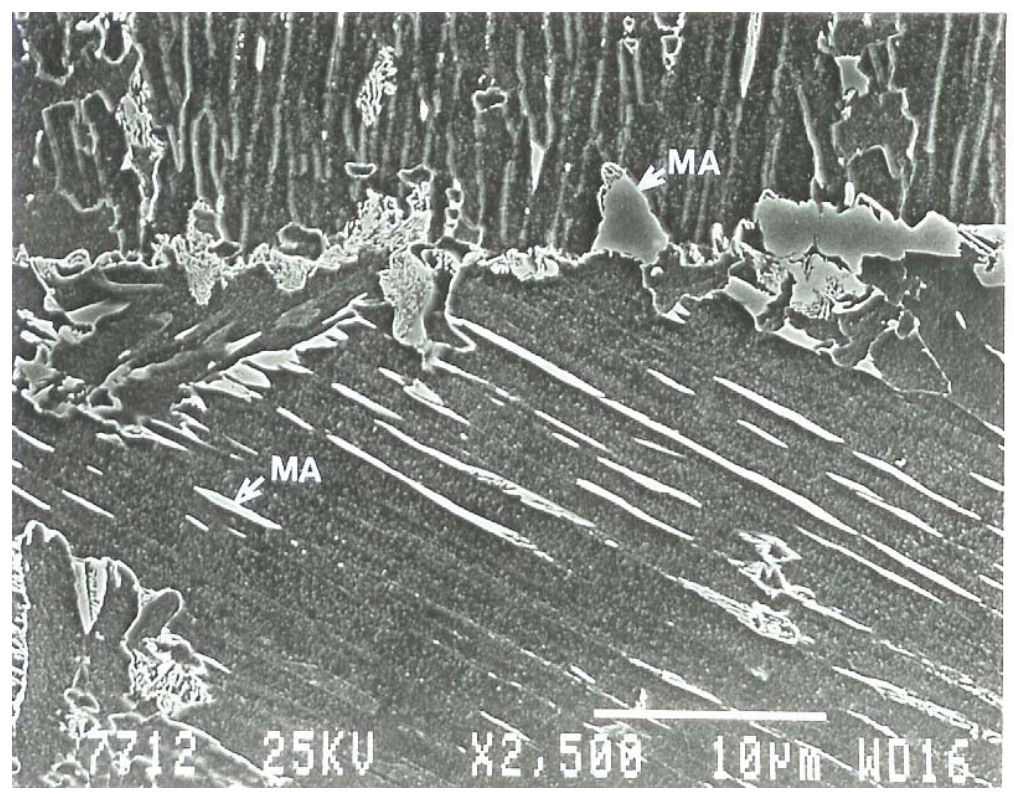

Fig 4a

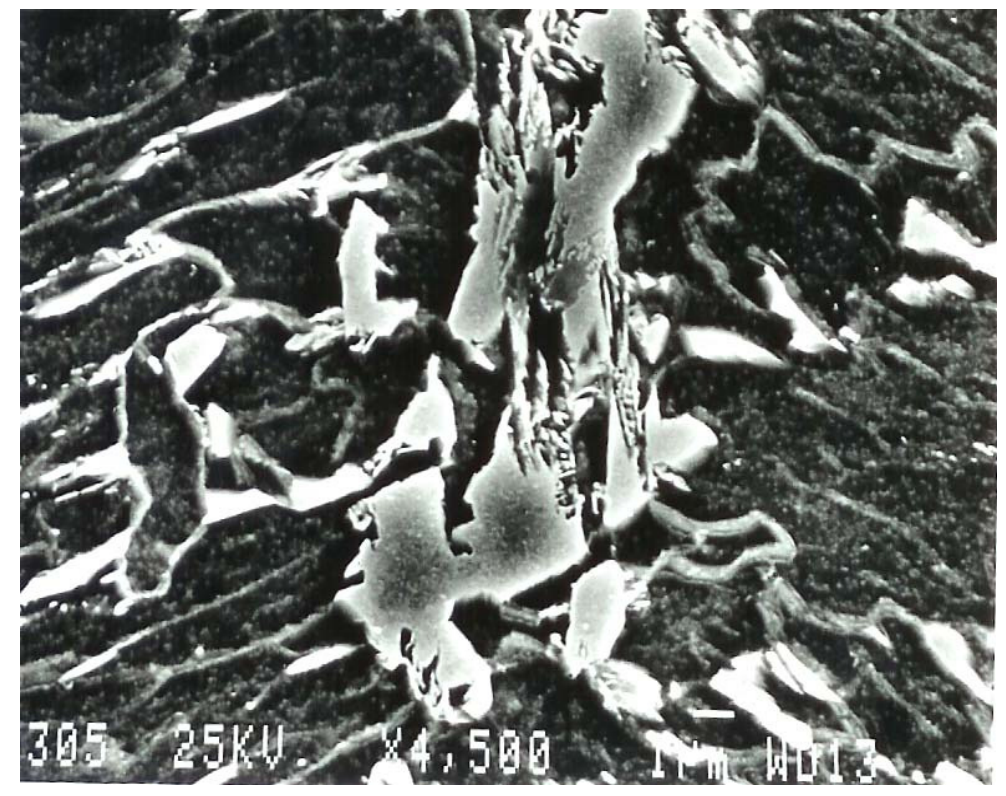


Fig $4 b$

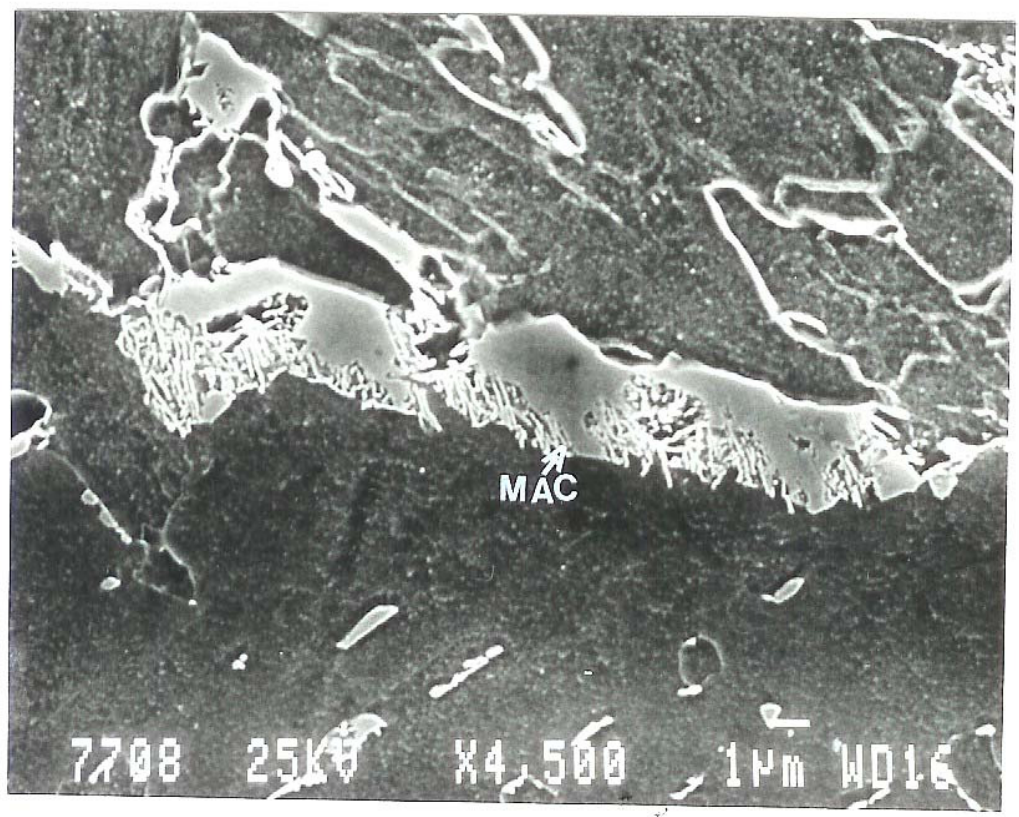

Fig. 4c

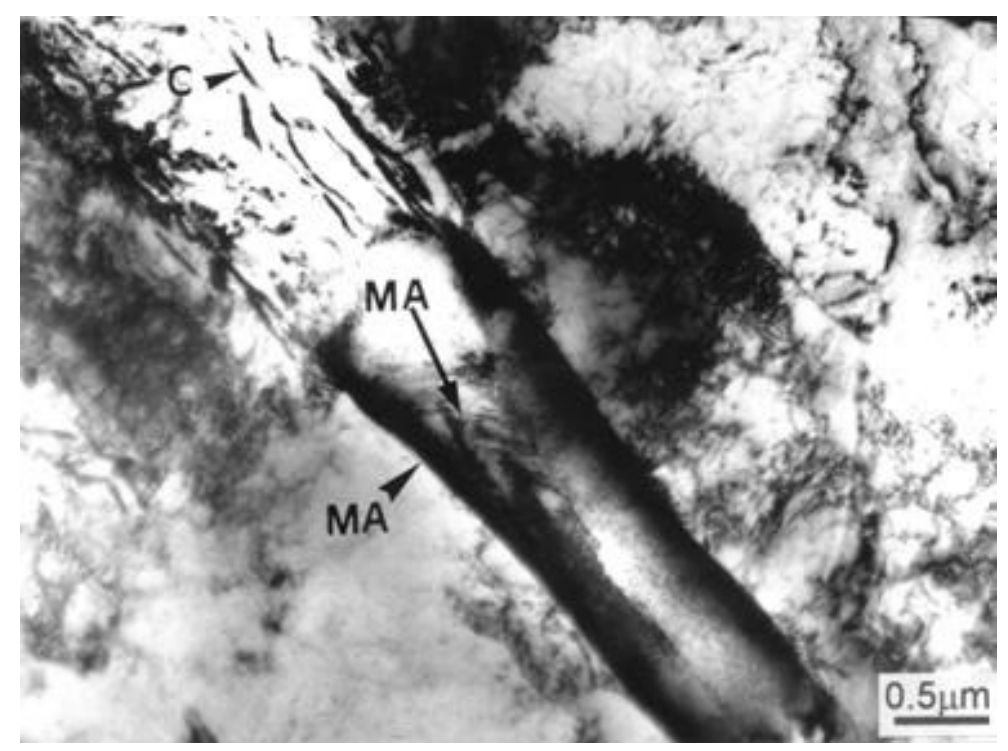


Fig. 5

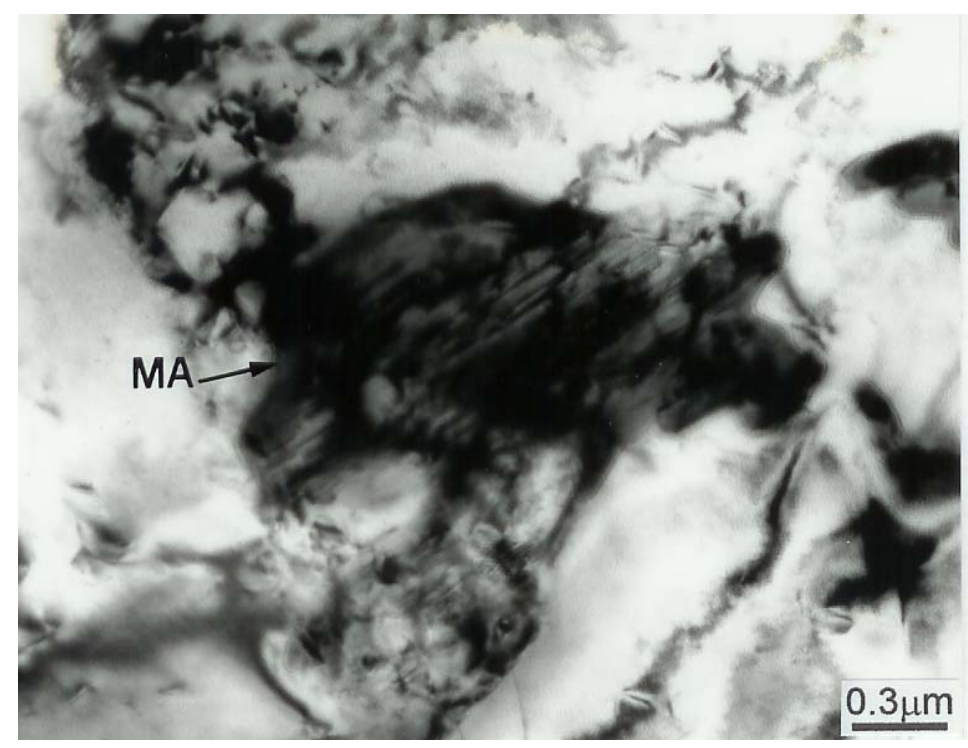

Fig 6a

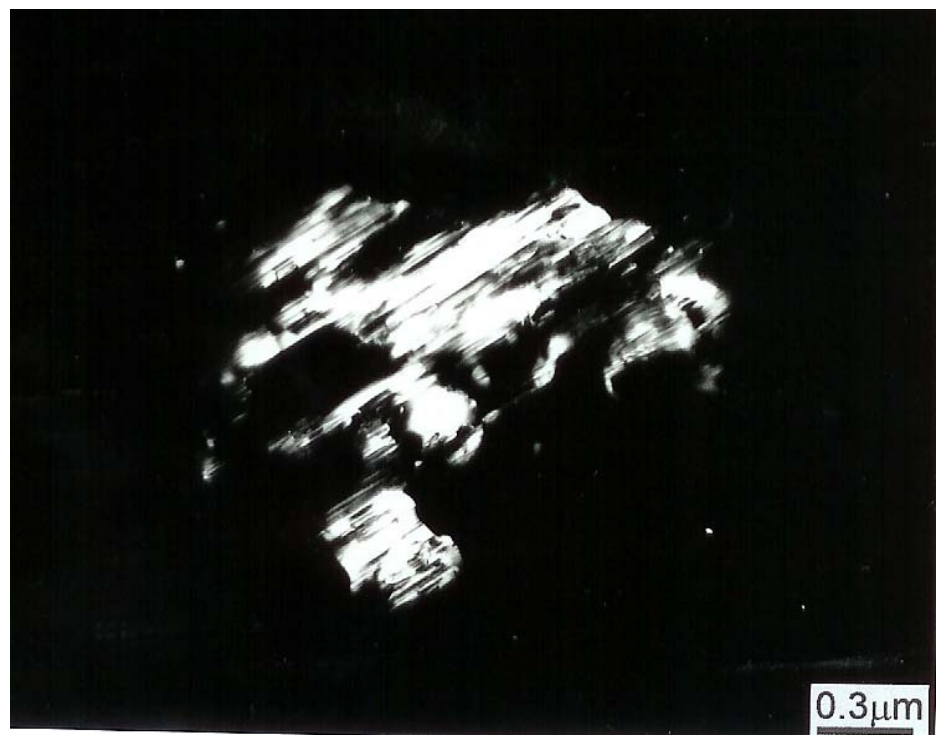


Fig $6 b$

IS

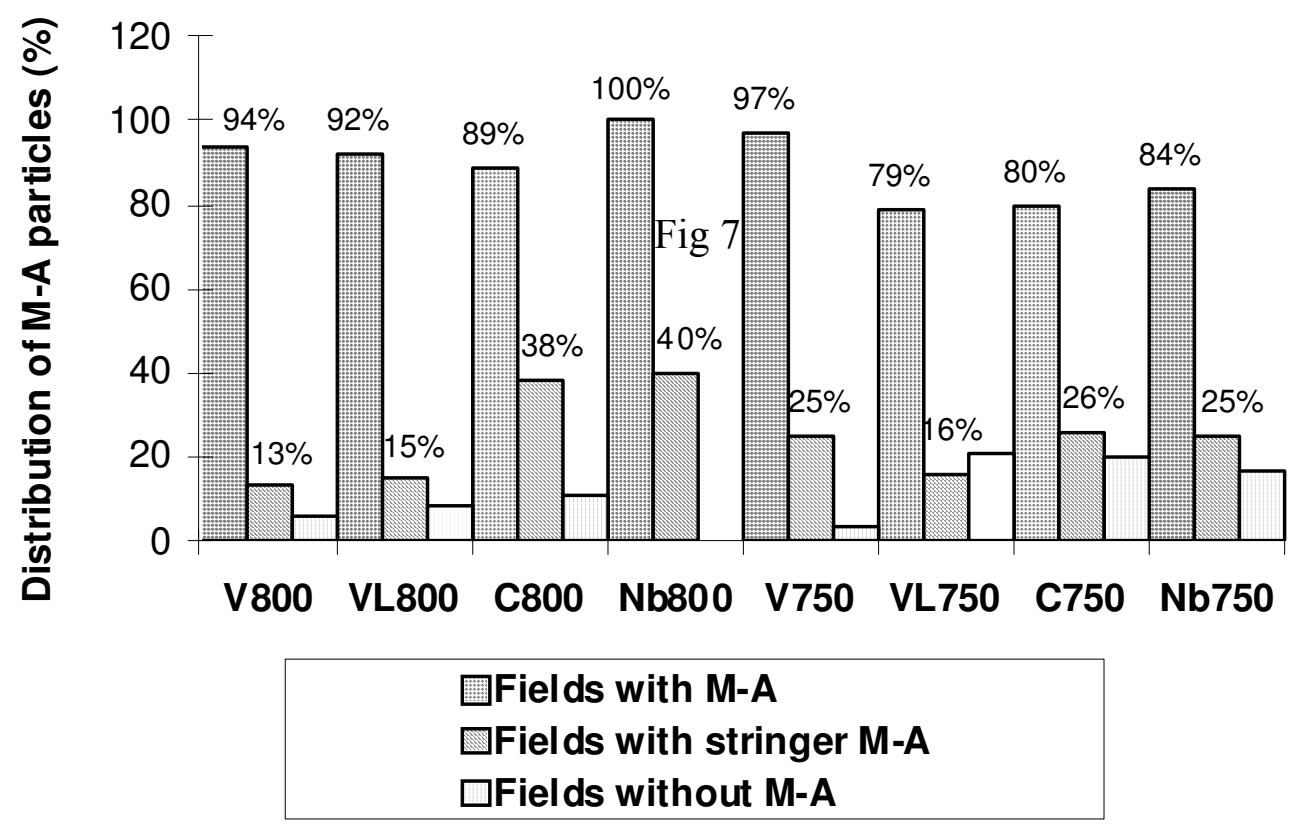

Fig 7 
$\square$ Grain boundaries with M-A

$\square$ Grain boundaries with connected M-A

$\square$ Grain boundaries without M-A

Fig 8

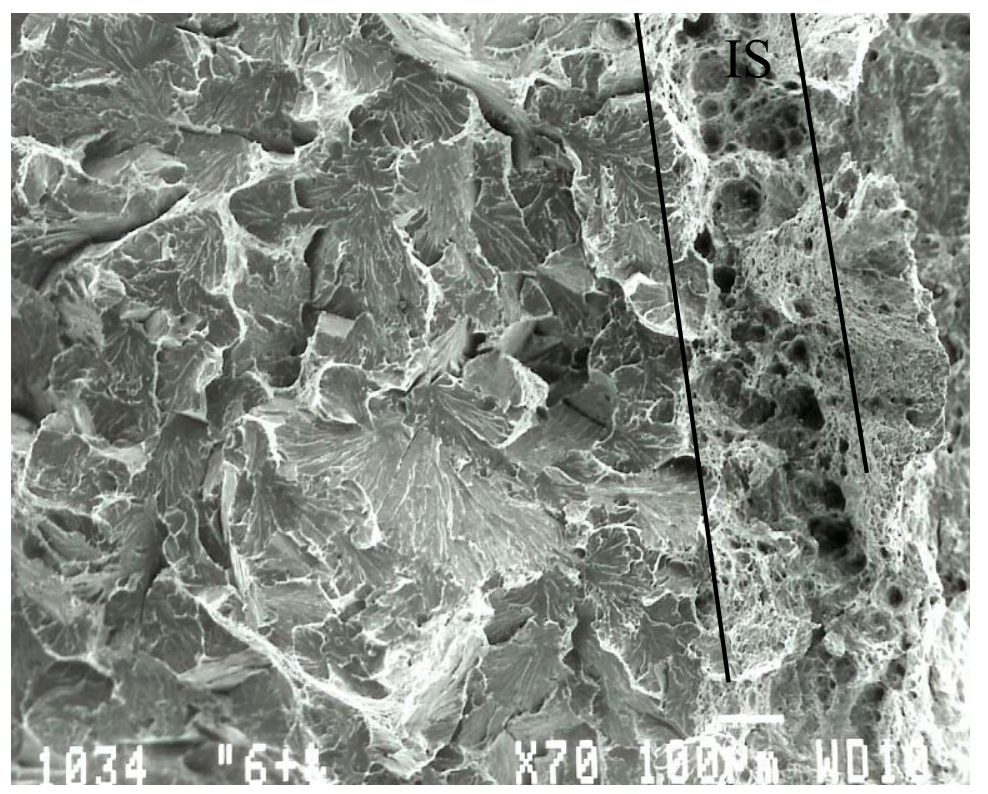

Fig 9

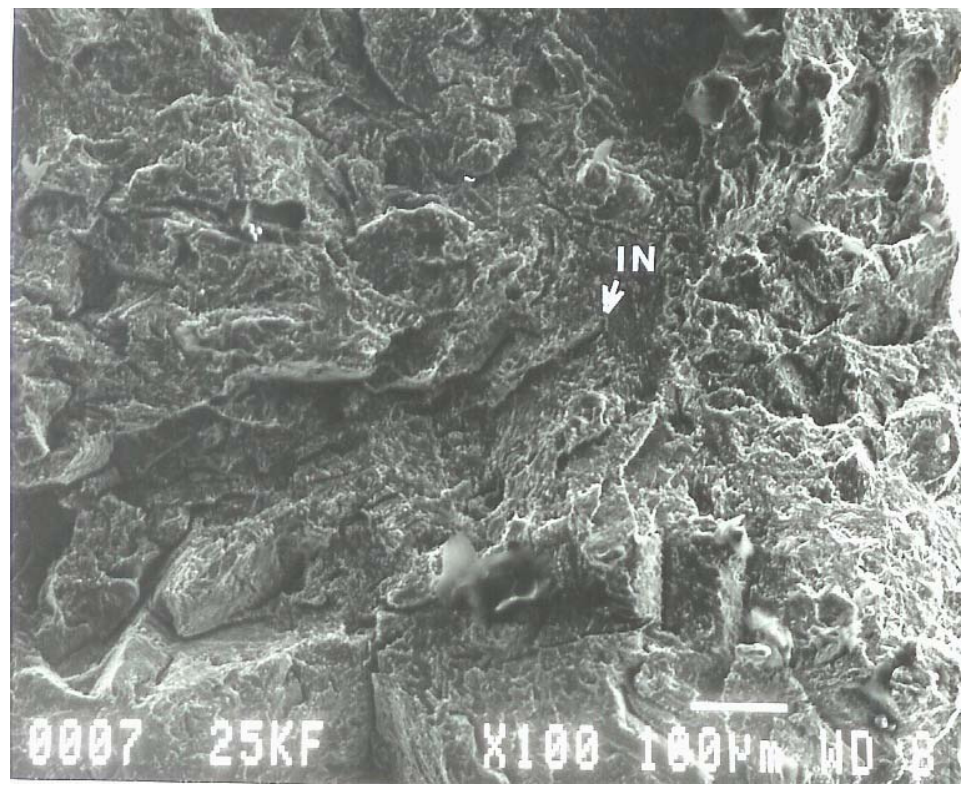


Fig 10

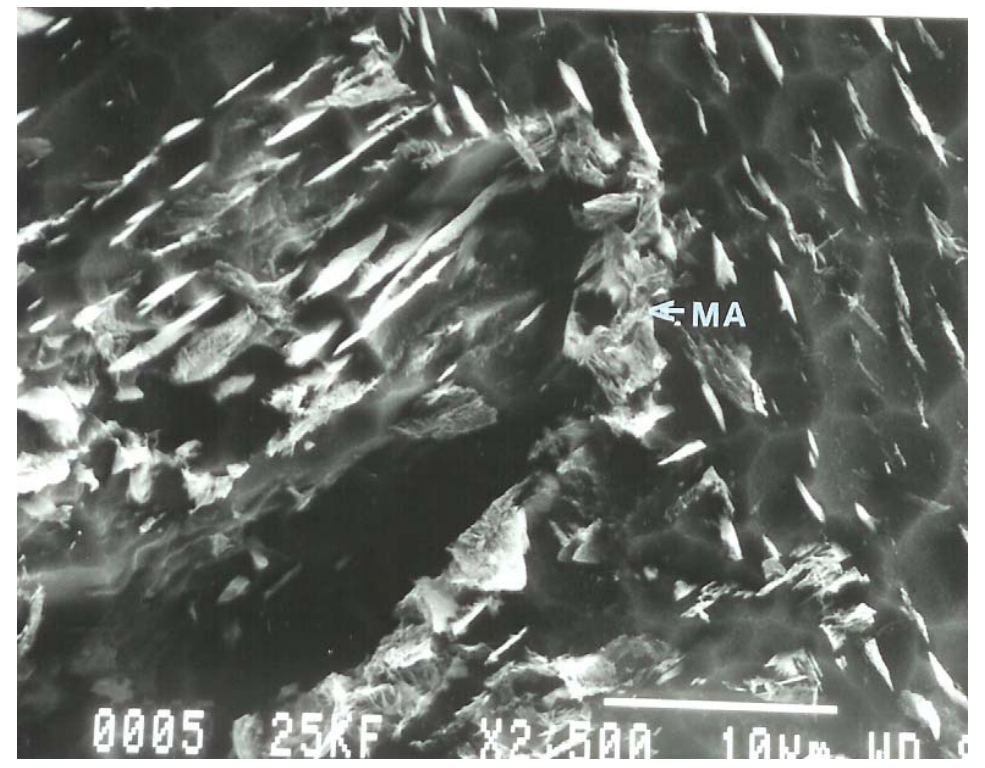

Fig 11

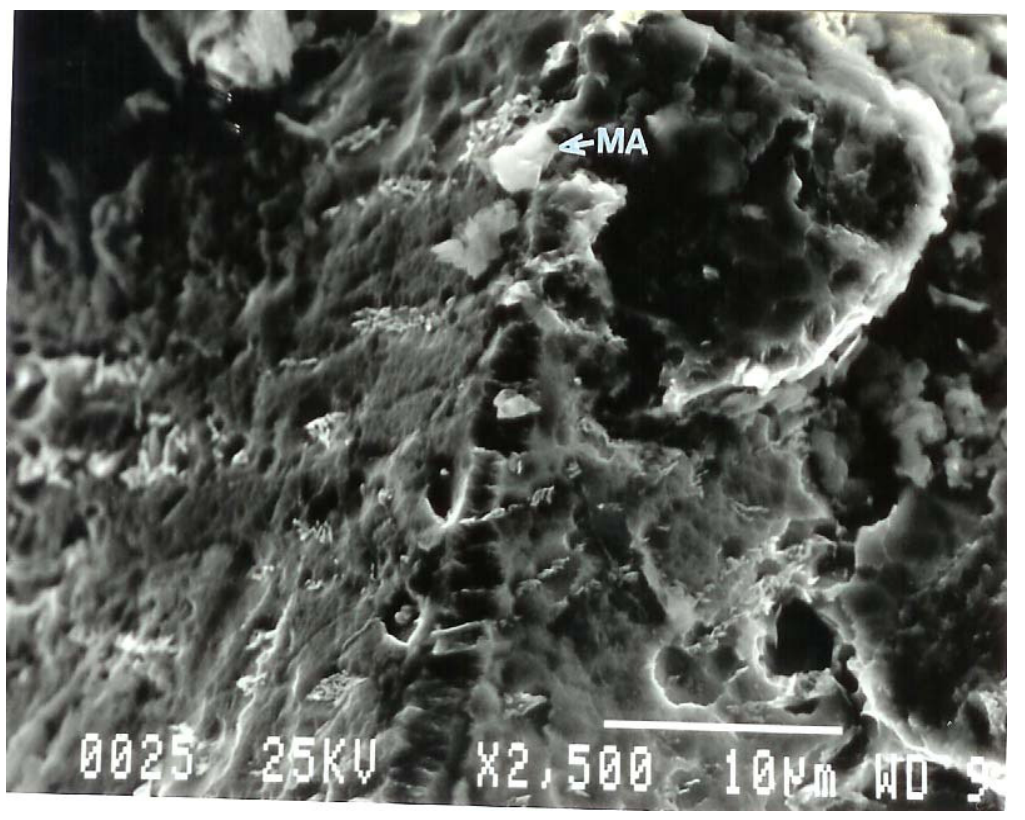


Fig. 12

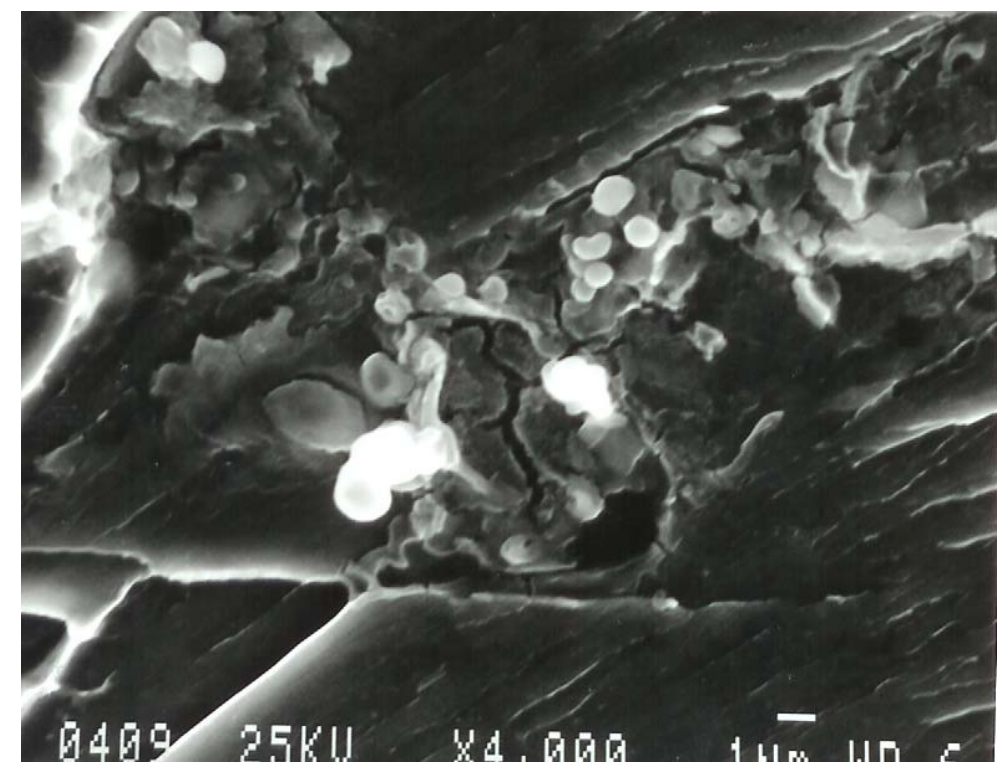

Fig 13

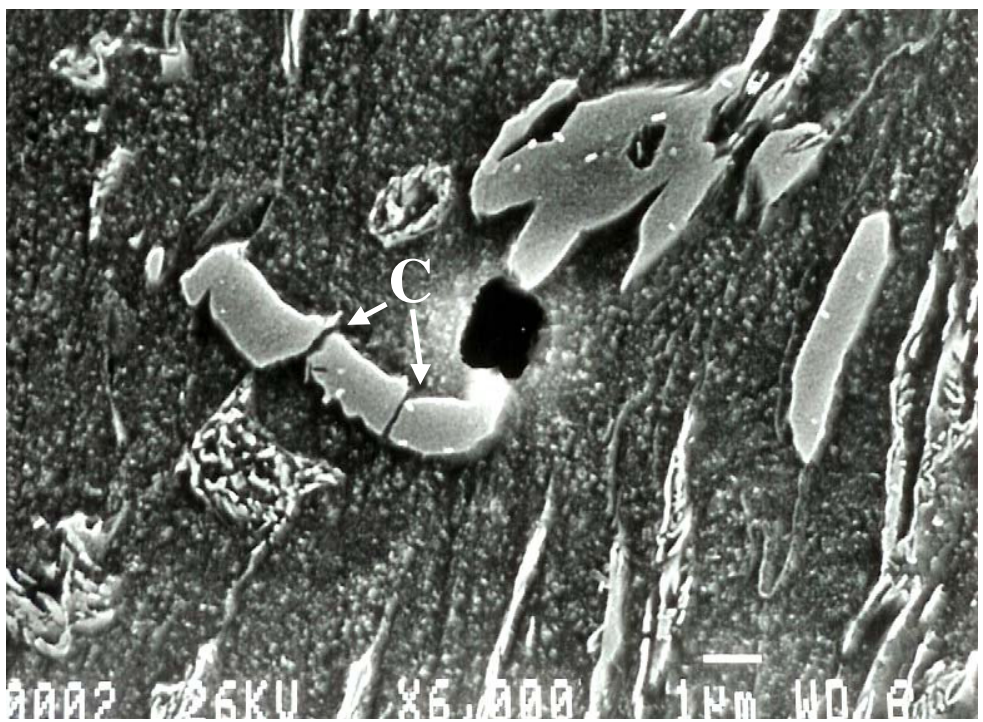

Fig 14 


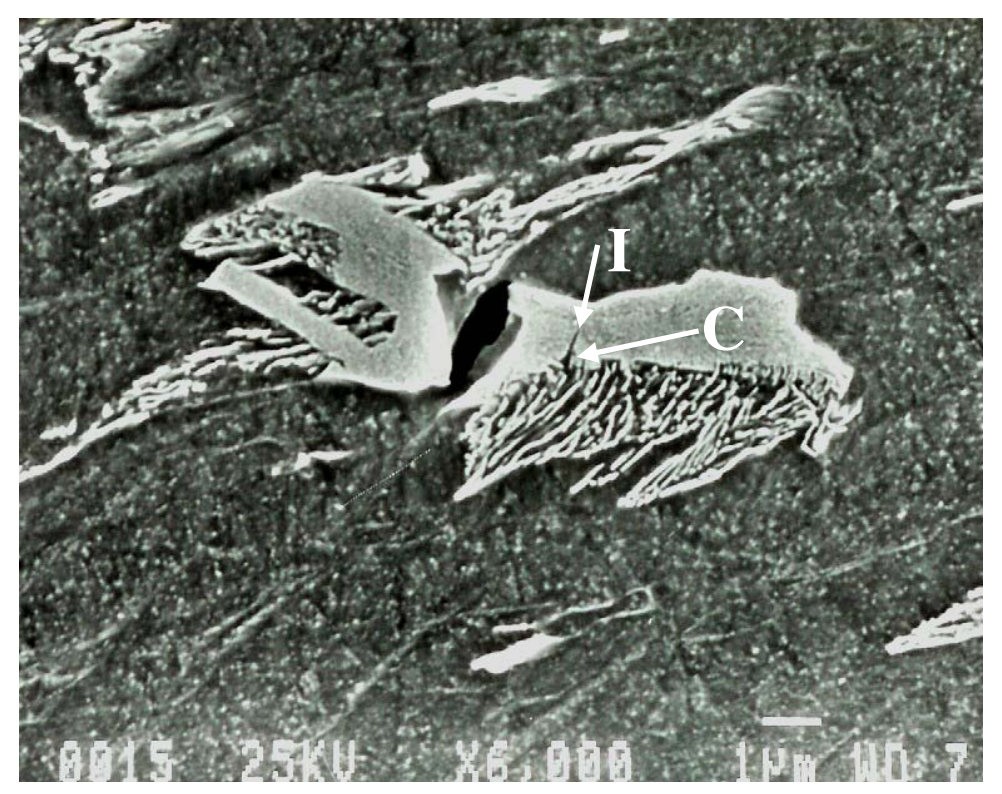

Fig 15

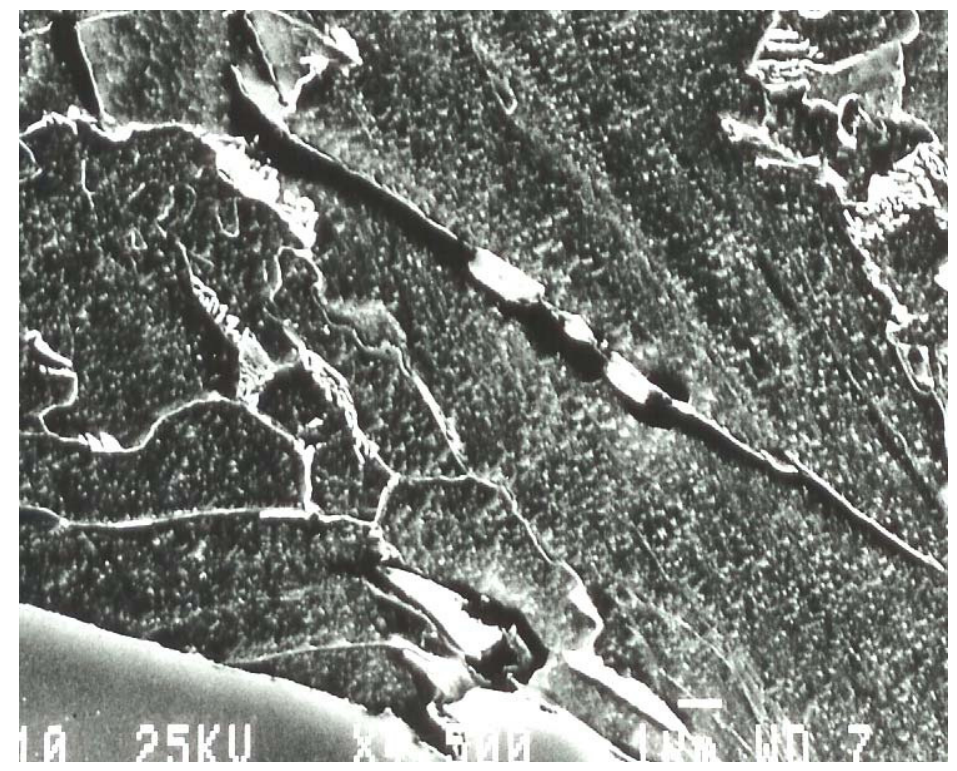


Fig 16

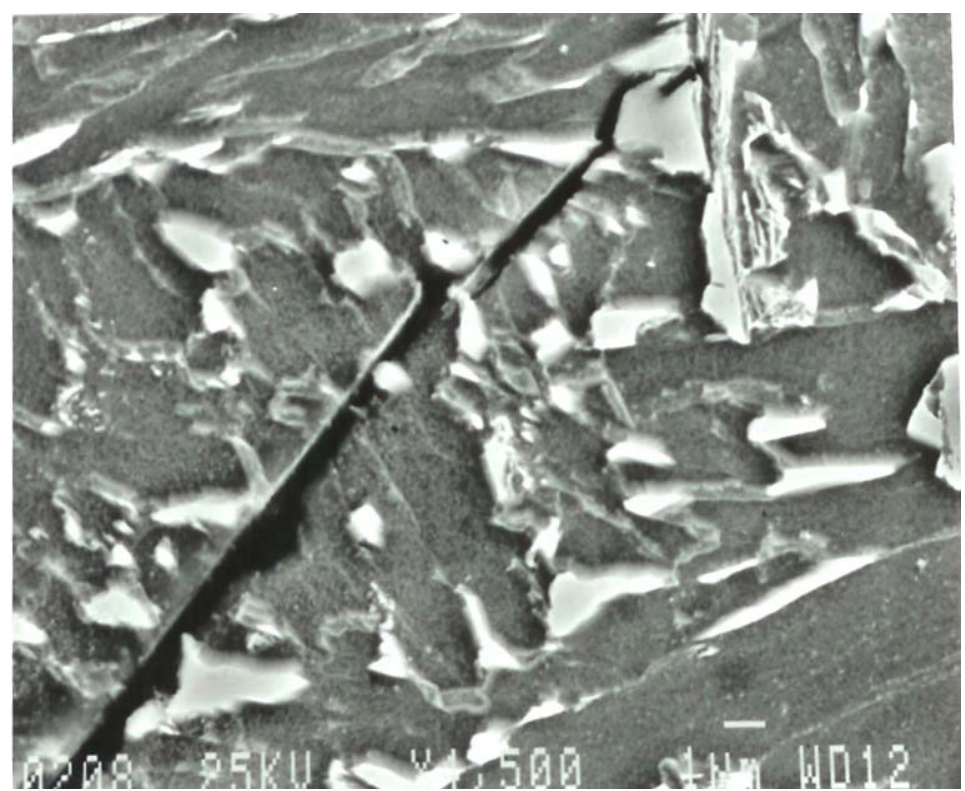

Fig 17

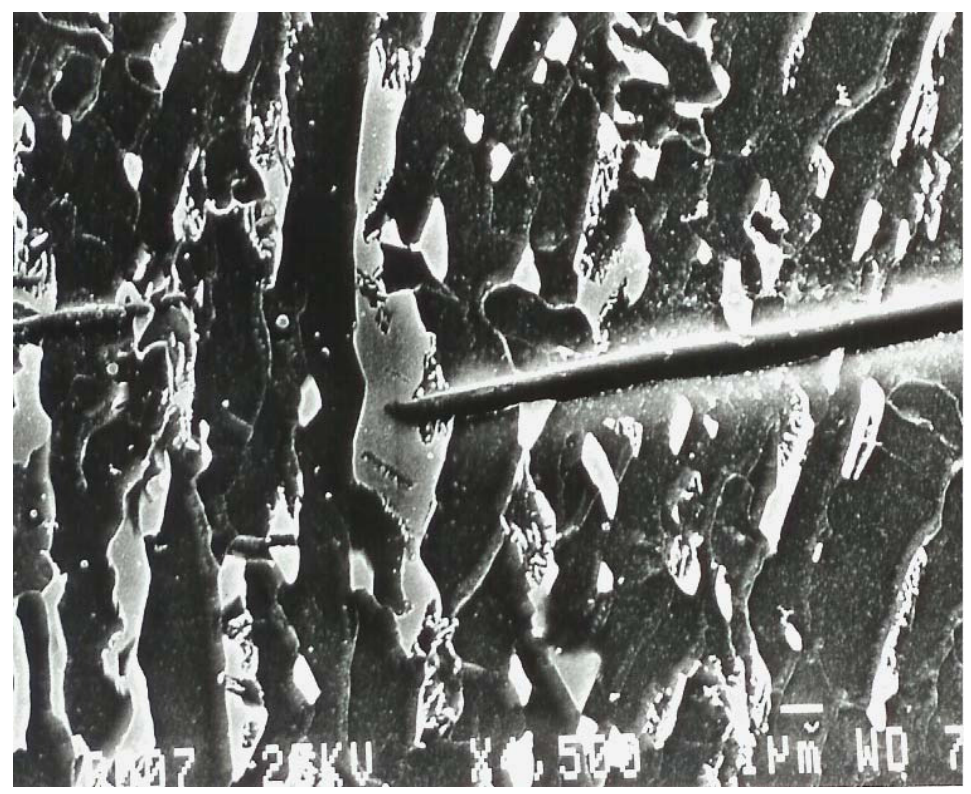


Fig 18

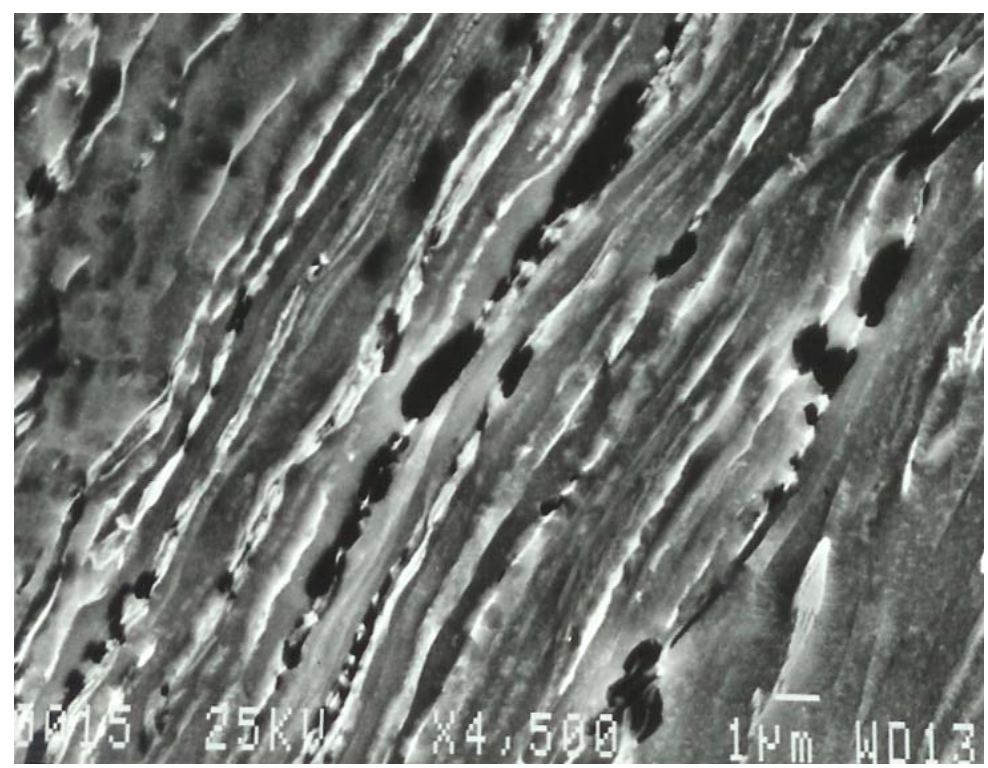

Fig 19

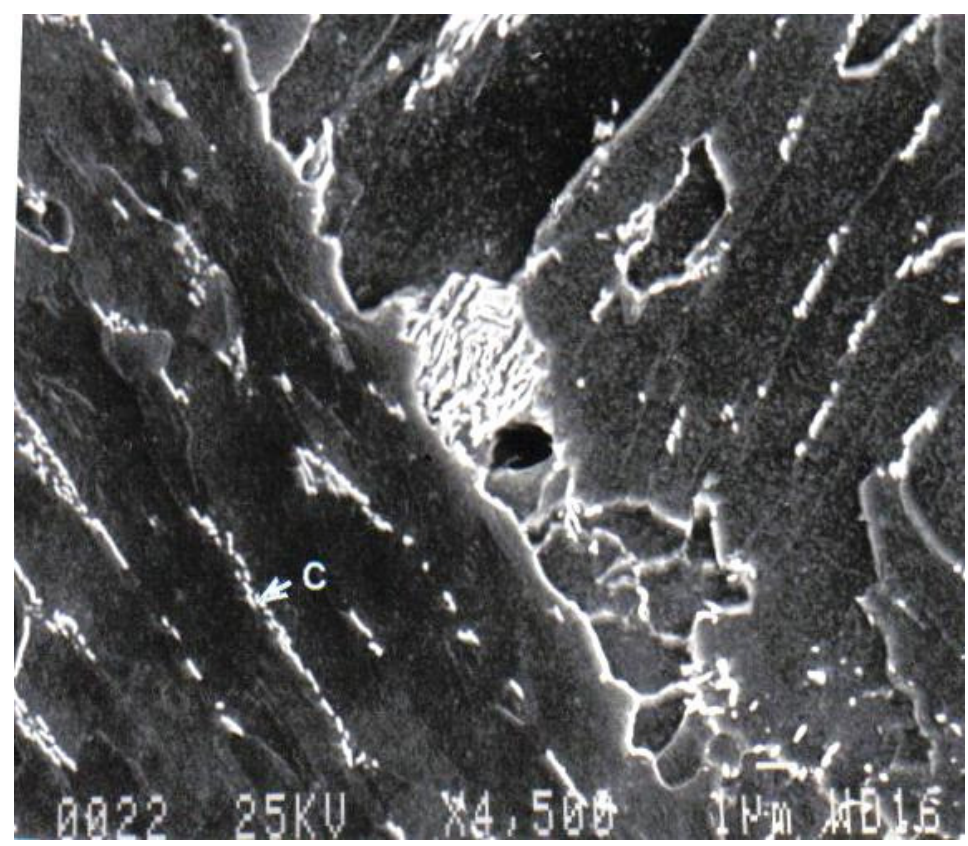

Fig 20 


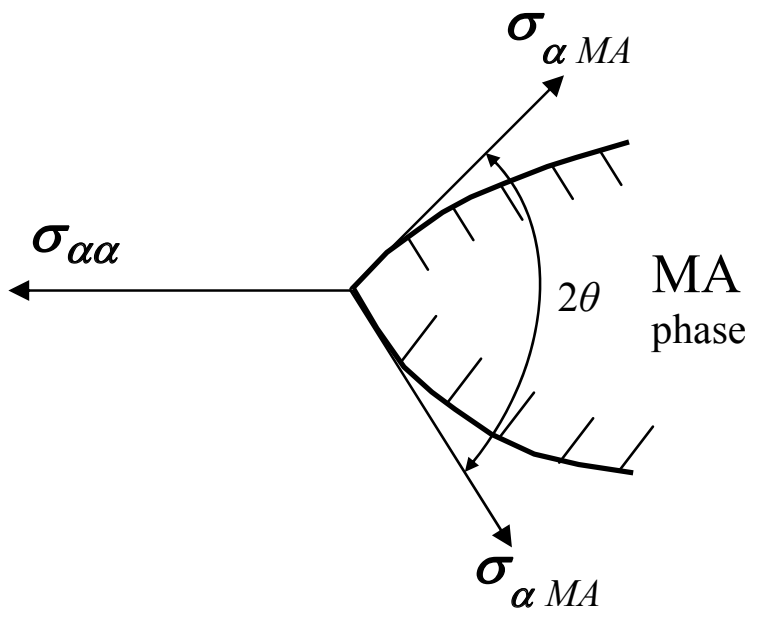

(a)

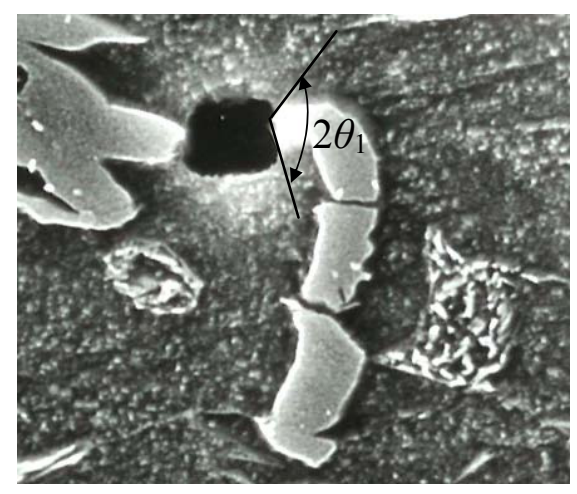

(b)

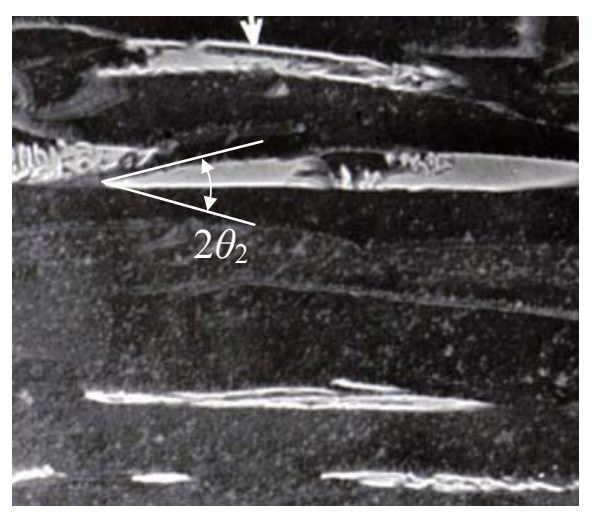

Fig 21 
